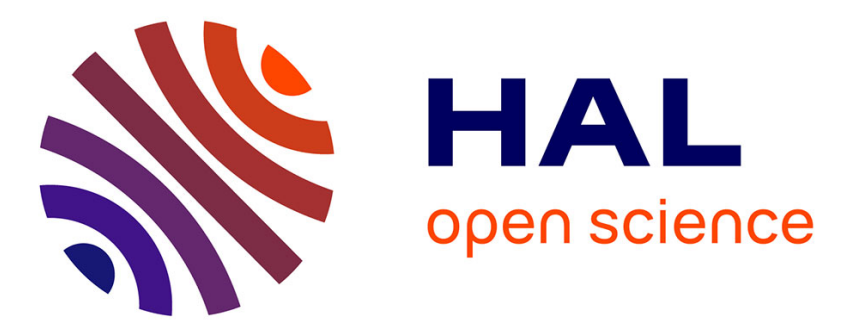

\title{
Effect of metallic iron on the oxidative dissolution of UO2 doped with a radioactive alpha emitter in synthetic Callovian-Oxfordian groundwater
}

Mélina Odorowski, Christophe Jégou, Laurent de Windt, Véronique Broudic, Gauthier Jouan, Sylvain Peuget, Christelle Martin

\section{To cite this version:}

Mélina Odorowski, Christophe Jégou, Laurent de Windt, Véronique Broudic, Gauthier Jouan, et al.. Effect of metallic iron on the oxidative dissolution of UO2 doped with a radioactive alpha emitter in synthetic Callovian-Oxfordian groundwater. Geochimica et Cosmochimica Acta, 2017, 219, pp.1 - 21. 10.1016/j.gca.2017.08.043 . hal-01657547

HAL Id: hal-01657547

https: / hal-mines-paristech.archives-ouvertes.fr/hal-01657547

Submitted on 3 Dec 2018

HAL is a multi-disciplinary open access archive for the deposit and dissemination of scientific research documents, whether they are published or not. The documents may come from teaching and research institutions in France or abroad, or from public or private research centers.
L'archive ouverte pluridisciplinaire HAL, est destinée au dépôt et à la diffusion de documents scientifiques de niveau recherche, publiés ou non, émanant des établissements d'enseignement et de recherche français ou étrangers, des laboratoires publics ou privés. 


\title{
Effect of metallic iron on the oxidative dissolution of $\mathrm{UO}_{2}$ doped with a radioactive alpha emitter in synthetic Callovian-Oxfordian groundwater
}

\author{
Mélina Odorowski ${ }^{\mathrm{a}, \mathrm{b}}$, Christophe Jegou ${ }^{\mathrm{a}}$, Laurent De Windt ${ }^{\mathrm{b}}$, Véronique Broudic ${ }^{\mathrm{a}}, \mathrm{Gauthier} \mathrm{Jouan}^{\mathrm{c}}$, \\ Sylvain Peuget ${ }^{\mathrm{a}}$, Christelle Martin ${ }^{\mathrm{d}}$ \\ ${ }^{a}$ Commissariat à l'Energie Atomique et aux Energies Alternatives, Centre de Marcoule, \\ DEN/DE2D/SEVT/LMPA, Bât. 166, BP 17171, 30207 Bagnols-sur-Cèze cedex, France \\ ${ }^{\mathrm{b}}$ MINES ParisTech, PSL Research University, Centre de Géosciences, 35 rue St Honoré, 77305 \\ Fontainebleau, France \\ ' Commissariat à l'Energie Atomique et aux Energies Alternatives, Centre de Marcoule, \\ DEN/DMRC/SFMA/LCC, Bât. 166, BP 17171, 30207 Bagnols-sur-Cèze cedex, France \\ ${ }^{d}$ Agence Nationale pour la gestion des Déchets Radioactifs, 1/7 rue Jean Monnet, 92298 Châtenay- \\ Malabry Cedex, France
}

\begin{abstract}
In the hypothesis of direct disposal of spent fuel in a geological nuclear waste repository, interactions between the fuel mainly composed of $\mathrm{UO}_{2}$ and its environment must be understood. The dissolution rate of the $\mathrm{UO}_{2}$ matrix, which depends on the redox conditions on the fuel surface, will have a major impact on the release of radionuclides into the environment. The reducing conditions expected for a geological disposal situation would appear to be favorable as regards the solubility and stability of the $\mathrm{UO}_{2}$ matrix, but may be disturbed on the surface of irradiated fuel. In particular, the local redox conditions will result from a competition between the radiolysis effects of water under alpha irradiation (simultaneously producing oxidizing species like $\mathrm{H}_{2} \mathrm{O}_{2}$, hydrogen peroxide, and reducing species like $\mathrm{H}_{2}$, hydrogen) and those of redox active species from the environment. In particular, $\mathrm{Fe}^{2+}$, a strongly reducing aqueous species coming from the corrosion of the iron canister or from the host rock, could influence the dissolution of the fuel matrix. The effect of iron on the oxidative dissolution of $\mathrm{UO}_{2}$ was thus investigated under the conditions of the French disposal site, a Callovian-Oxfordian clay formation chosen by the French National Radioactive Waste Management Agency (Andra), here tested under alpha irradiation. For this study, $\mathrm{UO}_{2}$ fuel pellets doped with a radioactive alpha emitter $\left({ }^{238 / 239} \mathrm{Pu}\right)$ were leached in synthetic Callovian-Oxfordian groundwater (representative of the French waste disposal site groundwater) in the presence of a metallic iron foil to simulate the steel canister. The pellets had varying levels of alpha activity, in order to modulate the concentrations of species produced by water radiolysis on the surface and to simulate the activity of aged spent fuel after 50 and 10000 years of alpha radioactivity decay. The experimental data showed that whatever the sample alpha radioactivity, the presence of iron inhibits the oxidizing dissolution of $\mathrm{UO}_{2}$ and leads to low uranium concentrations (between $4 \times 10^{-10}$ and $4 \times 10^{-9} \mathrm{M}$ ), through a reactional mechanism located in the very first microns of the $\mathrm{UO}_{2}$ /water reactional interface. The mechanism involves consumption of oxidizing species, in particular of $\mathrm{H}_{2} \mathrm{O}_{2}$ by $\mathrm{Fe}^{2+}$ at the precise place where these species are produced, and is accompanied by the precipitation of an akaganeite-type $\mathrm{Fe}^{3+}$ hydroxide on the surface. The higher the radioactivity of the samples, the greater the precipitation induced. Modeling has been developed, coupling chemistry with transport and based on the main reactional mechanisms identified, which enables accurate reproduction of the mineralogy of the system under study, giving the nature of the phases under observation as well as the location of their precipitation.
\end{abstract}


Obviously without excluding a potential contribution from the hydrogen produced by the anoxic corrosion of the iron foil, this study has shown that iron plays a major role in this oxidizing dissolution inhibition process for the system investigated (localized alpha radiolysis). This inhibitor effect associated with iron is therefore strongly dependent on the location of the redox front, which is found on the surface in the case of alpha irradiation $\mathrm{UO}_{2} /$ water reactional interface.

\section{Introduction}

The direct disposal of irradiated fuels in deep geological repositories is a major societal issue for several countries and in order to guarantee its long term safety this option requires a thorough knowledge of the processes which may lead to any release of radionuclides into the biosphere. The ability of the irradiated fuel $\mathrm{UO}_{2}$ matrix to withstand alteration by water is one of the major factors in this demonstration. Most of the sites chosen in Europe foresee disposal at a depth of between 300 and 500 meters is a reducing environment (granitic bedrock for the KBS-3 Swedish design, CallovianOxfordian COx or Boom clays for France and Belgium) whose chemical parameters ( $\mathrm{pH}$ and Eh) are intended to minimize any potential radionuclide releases. The redox potential is a particularly important parameter influencing the $\mathrm{UO}_{2}$ matrix stability (Shoesmith, 2000; Fanghänel et al., 2013; Ewing, 2015). Under reducing conditions $\mathrm{UO}_{2}$ solubility is very low, which favors the stability of the fuel matrix enclosing most of the radionuclides.

Nevertheless over the long term, the presence of an alpha self-irradiation field on the fuel surface generates, via water radiolysis, many sorts of molecular and radical species likely have a local impact on the redox conditions. In particular, changes to these redox conditions may lead to an oxidizing dissolution of $\mathrm{UO}_{2}$. The occurrence and degree of this phenomenon will depend on the intensity of the alpha irradiation field on the fuel surface. A threshold effect revealing a shift in an alteration mechanism controlled by $\mathrm{UO}_{2}$ solubility under anoxic conditions, without any change in the oxidation state of uranium, to a regime controlled by an oxidizing dissolution, has been observed in particular depending on the alpha activity of $\mathrm{UO}_{2}$ pellets (Rondinella et al., 2004; Muzeau et al., 2009). The position of this threshold is also strongly dependent on the environmental conditions. It has thus been shown that the presence of redox active species like hydrogen in the environmental water (anoxic corrosion of the containers) or iron may counteract the water radiolysis effects (Spahiu et al., 2004a; Liu et al., 2016).

As regards the influence of hydrogen, major efforts ranging from laboratory studies to the analysis of data available from natural analogs has enabled precise identification of the nature of the mechanisms involved, and in particular to demonstrate the catalytic properties of the surfaces $\left(\mathrm{UO}_{2}\right.$, epsilon particles, etc.) activating hydrogen at low temperature (Spahiu et al., 2004b; Carbol et al., 2009; Trummer and Jonsson, 2010; Broczkowski et al., 2010; Bruno and Spahiu., 2014). The absence of oxidation on the surface of $\mathrm{UO}_{2}$ under alpha irradiation in the presence of hydrogen has been demonstrated, but also a stop in the release of radionuclides from irradiated fuel. The presence of iron has been the subject of far fewer studies in the literature, particularly in the presence of a predominantly alpha irradiation field (Ödegaard-Jensen and Oversby, 2008; Amme et al., 2012). These studies agree on the fact that ferrous ions can consume oxidizing species like $\mathrm{H}_{2} \mathrm{O}_{2}$, potentially limit the oxidation of the $\mathrm{UO}_{2}$ matrix and cause considerable decreases in the concentrations of uranium in solution. For the effects of hydrogen as well as for those of iron, the notion of the redox front has been suggested (Ewing, 2015) in order to limit the oxidizing and reducing zones and to specify the location of the redox reactions. The exact location of this redox front remains an 
important question if iron is to be attributed a real inhibitor effect on $\mathrm{UO}_{2}$ oxidizing dissolution; in other words, perhaps the presence of iron does not lead to a stop in $\mathrm{UO}_{2}$ dissolution via the consumption of oxidizing radiolytic species, but rather to a considerable drop in uranium concentrations via a reduction process and secondary precipitation/sorption (Loïda et al., 1996; Cui et al., 2011).

In this context, it appears important to better explain the iron- $\mathrm{UO}_{2}$ matrix interaction mechanisms under alpha irradiation, and to manage to model these interactions by coupling chemistry with transport. The work presented here studied the influence of iron on the oxidizing dissolution of $\mathrm{UO}_{2}$ pellets doped with a radioactive alpha emitter under conditions similar to those of the potential French repository site, in a deep clay geological formation (reducing conditions and synthetic Callovian-Oxfordian water).

The radioactivity of the pellets doped with plutonium surrounds the threshold where a change in the $\mathrm{UO}_{2}$ alteration mechanisms can be observed, i.e. the passage from oxidizing $\mathrm{UO}_{2}$ dissolution to dissolution with no change in the oxidation state of the uranium. Obviously, a study of the most radioactive batch of $\mathrm{UO}_{2}$ remains very interesting even if it is extremely unlikely that water would come into contact with a waste package in a repository after just 50 years of disposal. High alpha activity enables the mechanisms to be amplified, and better highlights any possible environmental effect on $\mathrm{UO}_{2}$ oxidizing dissolution. The time it could take for water to come into contact with waste packages in a repository would also be highly dependent on the container design (thickness, etc.) and the predominance of a significant alpha irradiation field therefore cannot be excluded, even if this form of irradiation decays over time.

\section{Materials, experimental set-up and analyses}

\subsection{Materials}

\subsection{1. $\mathrm{UO}_{2}$ pellets doped with an alpha emitting radioactive element}

Three types of $\mathrm{UO}_{2}$ pellets were used for the experiments:

- Ref $\cup_{2}: \cup_{2}$ pellets used as reference;

- 50-years $\mathrm{UO}_{2}: \mathrm{UO}_{2}$ pellets doped with alpha emitters to reproduce the alpha activity of a $\mathrm{UOx}$ spent fuel with a burnup of $47 \mathrm{GWd} . \mathrm{t}_{\mathrm{HM}}{ }^{-1}$ after 50 years of radioactive decay;

- 10000-years $\mathrm{UO}_{2}: \mathrm{UO}_{2}$ pellets doped with alpha emitters to reproduce the alpha activity of a UOx spent fuel with a burnup of $47 \mathrm{GWd} . \mathrm{t}_{\mathrm{HM}}{ }^{-1}$ after 10000 years of radioactive decay.

The detailed compositions of these three types of $\mathrm{UO}_{2}$ pellets are presented in Table 1 . In the case of the $\mathrm{UO}_{2}$ pellets doped with alpha emitters, the isotopes ${ }^{238} \mathrm{Pu}$ and ${ }^{239} \mathrm{Pu}$ were used to fix the alpha activity. The total Pu content was $0.22 \mathrm{wt} \%$ for both 50 -years $\mathrm{UO}_{2}$ and 10000 -years $\mathrm{UO}_{2}$, and the alpha activity was fixed by adjusting the ratio of ${ }^{238} \mathrm{Pu}$ and ${ }^{239} \mathrm{Pu}$. The 50 -years $\mathrm{UO}_{2}$ pellets thus had an alpha activity of $385 \mathrm{MBq} \cdot \mathrm{guO2}^{-1}$ with a content of $0.060 \mathrm{wt} \%$ of ${ }^{238} \mathrm{Pu}$. For the 10000 -years $\mathrm{UO}_{2}$ pellets, an alpha activity of only $18 \mathrm{MBq} \cdot \mathrm{guo2}^{-1}$ was obtained with a content of $0.001 \mathrm{wt} \%$ of ${ }^{238} \mathrm{Pu}$.

The pellet fabrication process has already been described elsewhere (Muzeau et al., 2009). Two pellets polished on one face were used for each leaching test. Their thickness and their diameter were around $2 \mathrm{~mm}$ and $8 \mathrm{~mm}$ respectively, while the $\mathrm{UO}_{2}$ pellet density was $10.75 \mathrm{~g} . \mathrm{cm}^{-3}$. Before the experiments, all the pellets were annealed for $5 \mathrm{~h}$ at $1100{ }^{\circ} \mathrm{C}$ under an $\mathrm{Ar} / \mathrm{H}_{2} 4 \%$ atmosphere to restore the $\mathrm{UO}_{2}$ stoichiometry. Moreover, the pellets were subjected to 10 one-hour pre-leaching 
cycles in a carbonated water $\left(\mathrm{NaHCO}_{3} 10^{-3} \mathrm{M}\right)$ before each experiment to remove any surface oxidation layer and obtain an identical initial reference state for all the pellets.

[TABLE 1]

\subsubsection{Iron foil}

Iron foils were placed in the system to simulate the iron canister and to stabilize the redox conditions in the reactor. Rolled 99.99\% pure iron foils were purchased from Goodfellow. Their size was $2.5 \mathrm{~cm}$ by $2.5 \mathrm{~cm}$ for a thickness of $125 \mu \mathrm{m}$ and a weight of around $0.64 \mathrm{~g}$. One iron foil was used per experiment. Before being set up in the reactors, the foils were rinsed in ethanol and ultrasoundcleaned for 2 minutes.

\subsection{Leaching procedure}

Six leaching tests were performed under static conditions in synthetic $\mathrm{COx}$ water under $\mathrm{Ar} / \mathrm{CO}_{2} 3000$ ppm atmosphere. The differences between the experiments came from the different kinds of $\mathrm{UO}_{2}$ pellets used, and whether or not iron foil was present in the system. The conditions for all the experiments are summarized in table 2 .

\section{[TABLE 2]}

\subsubsection{Equipment and setup}

Due to the Pu content of the $\mathrm{UO}_{2}$ pellets, all the experiments were performed inside a glove box with slightly lower pressure compared to the laboratory atmosphere. The atmosphere inside the glove box was argon $\left(\mathrm{O}_{2}<1 \mathrm{ppm}\right)$ in order to ensure anoxic conditions. The leaching reactors were airtight and all the parts in contact with solution were in titanium dioxide. Titanium is relatively inert chemically for radiolytical species, and as the objective was to study the influence of iron on $\mathrm{UO}_{2}$ dissolution any possible iron contribution from the experimental equipment had to be avoided. Samples were collected without opening the reactor through a sampling valve, thanks to the overpressure inside the reactor.

\subsubsection{Leaching experiments in synthetic COx water}

The leaching solution was a synthetic groundwater representative of Callovian-Oxfordian groundwater. A simplified groundwater composition was calculated by the BRGM (French Office of Geological and Mining Research) and validated by Andra (French National Radioactive Waste Management Agency) from analyses of samples coming from the site of the Meuse/Haute-Marne laboratory (France) and from Andra's regional boreholes (Gaucher et al., 2006; Tournassat et al., 2008). The fabrication procedure of the synthetic Callovian-Oxfordian groundwater has been described elsewhere (Tribet et al., 2010). Its composition is given in table 3, and the $\mathrm{pH}$ was around 6.5-7.0.

\section{[TABLE 3]}

Two $\mathrm{UO}_{2}$ pellets were placed in a reactor containing $150 \mathrm{~mL}$ of synthetic COx groundwater solution. The system was then purged with a mixture of $\mathrm{Ar} / \mathrm{CO}_{2} 3000 \mathrm{ppm}$ for at least $2 \mathrm{~h}$ and finally pressurized at 3.5 bars. Solution samples were regularly collected for analyses. The last sample was also filtered at $0.45 \mu \mathrm{m}$ (VWR cellulose acetate filter) and ultra-filtered at $0.02 \mu \mathrm{m}$ (Whatman Anodisc inorganic filter) to evaluate the presence of colloids. 


\subsubsection{Leaching experiments in synthetic $\mathrm{COx}$ water and in presence of iron}

Iron pre-corrosion phase

The iron foil was first pre-corroded in $180 \mathrm{~mL}$ of synthetic COx water for around $80-90$ days in the absence of the $\mathrm{UO}_{2}$ pellets. This first step was intended to ensure the presence of corrosion products on the iron foil surface, to obtain a solution chemistry containing $\mathrm{Fe}^{2+}$ ions not initially present in the synthetic COx water, and to have reducing conditions when the $\mathrm{UO}_{2}$ pellets were introduced at a later date. The iron foil was slightly curved to enable maximum contact with water, and placed on the platform immediately under the pellet support. Once the leaching reactor had been closed, it was purged with a mixture $\mathrm{Ar} / \mathrm{CO}_{2} 3000 \mathrm{ppm}$ for $2 \mathrm{~h} 30$ and then put under a pressure of $3.5 \mathrm{bars}$. The leaching solution was regularly sampled over time.

$\mathrm{UO}_{2}$ corrosion phase

After the iron pre-corrosion phase, the reactor was opened to add two $\mathrm{UO}_{2}$ pellets, which were placed on a support above the iron foil. The reactor was then closed again, purged with a mixture of $\mathrm{Ar} / \mathrm{CO}_{2} 3000 \mathrm{ppm}$ for $30 \mathrm{~min}$, and returned to a pressure of 3.5 bars. Samples of the leaching solution were regularly collected over time. The last sample was filtered at $0.45 \mu \mathrm{m}$ (VWR cellulose acetate filter) and ultra-filtered at $0.02 \mu \mathrm{m}$ (Whatman Anodisc inorganic filter) to evaluate the presence of colloids. The choice of this cut-off threshold remains arbitrary and the presence of colloids smaller than $20 \mathrm{~nm}$ cannot be ruled out.

\section{Stopping of the leaching experiments}

At the end of the experiment, the pellets and the iron foil were removed from the solution, dried on a Kimtech( wiper and stored under argon until the surface characterizations could be done.

In the case of the 50-years $\mathrm{UO}_{2}$ experiment, the leaching solution volume was adjusted at $180 \mathrm{~mL}$ with ultrapure water and $\mathrm{HNO}_{3} 15 \mathrm{M}$, for an acidity of $0.5 \mathrm{M}$. The aim here is mainly to recover the uranium sorbed on the walls of the $\mathrm{TiO}_{2}$ reactor. After the acidification period, the reactor was emptied and finally rinsed for $24 \mathrm{~h}$ successively with $200 \mathrm{~mL}$ of $\mathrm{HNO}_{3} 2 \mathrm{M}, 200 \mathrm{~mL}$ of $\mathrm{HNO}_{3} 0.5 \mathrm{M}$, and 3 times with $230 \mathrm{~mL}$ of ultrapure water. Solution samples were taken and analyzed for each acidification and rinse. These acid rinses permitted the total quantification of colloids and species sorbed or precipitated on the $\mathrm{TiO}_{2}$ reactor.

In the case of the 10000 years $\mathrm{UO}_{2}$ experiment, the leaching solution was firstly transferred into a bottle before acidification. The same protocol of acidification and rinses as for the 50-years $\mathrm{UO}_{2}$ experiment was then applied. This protocol improvement enabled complete differentiation between the fraction in the leachate and the fraction sorbed/precipitated onto the $\mathrm{TiO}_{2}$ reactor.

In the case of the blank experiment, the same protocol was applied but in the absence of $\mathrm{UO}_{2}$ pellets.

Acid rinsing of the iron foils

After surface characterization, the iron foils were rinsed for 30 min in $10 \mathrm{~mL}$ of $\mathrm{HNO}_{3} 0.5 \mathrm{M}$ to quantify the uranium adsorbed or precipitated onto the foil. A sample of $2 \mathrm{~mL}$ was then taken and acidified at $3 \mathrm{M}$ with $\mathrm{HNO}_{3} 15 \mathrm{M}$ to dissolve the Fe-precipitates formed in the solution.

\subsection{Analyses}

\subsubsection{Solution}


All the samples collected underwent different analyses carried out in the Atalante facility LMPA laboratory (CEA Marcoule).

Eh and $\mathrm{pH}$ are two important parameters for uranium chemistry. These were monitored ex-situ and exceptionally in-situ, when the reactor was opened for the pellets introduction and at the end of the experiments. Eh and pH were measured with the WTW SenTix ORP electrode and the Mettler Toledo Ingold LoT406-M6-DXK-S7/25 electrode respectively.

Uranium and plutonium concentrations were followed, as they could be indicators of the $\mathrm{UO}_{2}$ dissolution. Uranyl ion concentrations were measured by laser-induced kinetic phosphorescence with a Chemchek KPA11 Kinetic Phosphorescence Analyzer (quantification limit $0.1 \mu \mathrm{g} . \mathrm{L}^{-1}$ ). Plutonium was measured by alpha-spectrometry and alpha-counting with a Canberra Alpha Analyst spectrometer and a Eurisys IN 20 alpha-beta multidetector counter. The minimal total activity quantifiable was $0.1 \mathrm{~Bq} \cdot \mathrm{mL}^{-1}$. Only the uranium concentration evolutions will be described hereafter, as the plutonium content was generally below the detection limits.

Finally, the concentrations of all the ions composing the COx water and the Fe were followed, to detect any massive precipitation. $\mathrm{Fe}, \mathrm{Ca}, \mathrm{Mg}, \mathrm{K}, \mathrm{Na}, \mathrm{Si}$, and $\mathrm{Sr}$ concentrations were analyzed using Jobin Yvon JY46 ICP-AES (Inductively Coupled Plasma Atomic Emission Spectroscopy) with a concentration range between $10 \mu \mathrm{g} \cdot \mathrm{L}^{-1}$ and $100 \mathrm{mg} \cdot \mathrm{L}^{-1}$ depending on the element. The concentrations of the anions $\mathrm{Cl}^{-}$and $\mathrm{SO}_{4}{ }^{2-}$ were assessed by ion chromatography with a METROHM COMPACT 881 PRO chromatograph (concentration range from 0.1 to $1 \mathrm{mg} \cdot \mathrm{L}^{-1}$ ).

\subsubsection{Gas}

The gaseous phase in the reactor was analyzed by gas chromatography at the end of each experiment. In the case of the experiments containing an iron foil, its anoxic corrosion was expected to release $\mathrm{H}_{2}(\mathrm{~g})$, and an additional analysis was performed at the end of the iron pre-corrosion phase before opening the reactor to put in the pellets. These analyses were performed with a MicroGC 3000 gas chromatograph from SRA Instruments set up in the glove box. This device enables the detection of gaseous $\mathrm{H}_{2}, \mathrm{O}_{2}, \mathrm{~N}_{2}$ and $\mathrm{He}$, with a detection limit of $1 \mathrm{ppm}$.

\subsubsection{Surfaces}

The $\mathrm{UO}_{2}$ pellets and pieces of iron foil were observed by Scanning Electron Microscopy (SEM) with a ZEISS SUPRA 55 microscope in the LCC laboratory (formerly LEMA) at the Atalante facility. This apparatus is equipped with an EDS X-act and a WDS Oxford Instruments detectors. An accelerating voltage of between 5 and $20 \mathrm{kV}$ with a current of $0.62 \mathrm{nA}$ were applied for imaging, and $20 \mathrm{kV}$ with a current of 39 nA for EDX analyses.

Raman spectroscopy was then performed to identify the nature of the precipitates observed. A Jobin-Yvon Labram HR800 spectrometer with a laser excitation at $532 \mathrm{~nm}$ coupled to an optical microscope was used. The microscope is set up in a hot cell while the Raman spectrometer is placed outside the cell and linked to the microscope by optical fibers. Samples were observed through a x100 lens and the output power was adapted for each precipitate in order to avoid any oxidation under the beam.

\section{Reactive transport modeling}

\subsection{Code and thermodynamic database}


The reactive transport modeling was performed with the HYTEC code (van der Lee et al., 2003). HYTEC is based on a finite element discretization in a representative elementary volume (REV) approach, with a sequential iterative operator-splitting method for coupling between chemistry and transport. In this experimental set-up without stirring, the transport of species was driven by diffusion within the solution, especially between the $\mathrm{UO}_{2}$ pellets and the iron foil separated by just a few centimeters. A diffusion coefficient of $10^{-9} \mathrm{~m}^{2} / \mathrm{s}$ was considered in the calculations.

Globally all the chemical reactions were calculated under thermodynamic equilibrium, except for $\mathrm{H}_{2} \mathrm{O}_{2}$ radiolytic generation, $\mathrm{UO}_{2}$ dissolution and metallic iron corrosion that were under kinetic control as detailed below. However, the hydrogen $\mathrm{H}_{2}(\mathrm{aq})$ produced by the anoxic corrosion of iron was fully decoupled from the redox reactions in the modeling, i.e. it could not reduce $\mathrm{H}_{2} \mathrm{O}_{2}$ or $\mathrm{U}(\mathrm{VI})$ in solution. Furthermore, $\mathrm{H}_{2} \mathrm{O}_{2}(\mathrm{aq})$ could react with $\mathrm{Fe}(\mathrm{II})$ and $\mathrm{U}$ (IV) but the decomposition of hydrogen peroxide $\mathrm{H}_{2} \mathrm{O}_{2}(\mathrm{aq})$ (disproportionation into oxygen $\mathrm{O}_{2}(\mathrm{aq})$ and water $\mathrm{H}_{2} \mathrm{O}$ ) was forbidden in the modeling.

The thermodynamic database "ThermoChimie" was used for all the simulations (Giffaut et al., 2014). ThermoChimie developments focus on evaluating specific conditions of the near field of radioactive waste, and the database is up-to-date with respect to the NEA compilation on the thermodynamics of fission products and actinides (Guillaumont et al., 2003). The reactions of formation, as well as the associated constants at $25^{\circ} \mathrm{C}$ for the minerals considered in the modeling, are given in table 4 .

\section{[TABLE 4]}

\subsection{Dissolution laws and kinetics}

The modeling undertaken for this study took into account the main mechanisms and associated kinetics for the system studied, and was not intended to describe the complexity of the elementary processes, including the irradiation involved. One of the objectives in particular was to determine to what extent such modeling is sufficient to describe the experimental results and of use in their interpretation. The modeling was carried out for the 50 -years $\mathrm{UO}_{2}$ pellets only.

\subsubsection{Production of radiolytic $\mathrm{H}_{2} \mathrm{O}_{2}(\mathrm{aq})$}

Radiolytic oxidants produced by radiation-induced water radiolysis may cause the oxidative dissolution of a $\mathrm{UO}_{2}$ matrix. In particular, under alpha irradiation, the most important species to be considered regarding $\mathrm{UO}_{2}$ dissolution is $\mathrm{H}_{2} \mathrm{O}_{2}$ (Ekeroth et al., 2006; Lousada et al., 2013; Liu et al., 2016). The generation of $\mathrm{H}_{2} \mathrm{O}_{2}(\mathrm{aq})$ was introduced in the model according to the following rate law:

$$
\frac{d\left[\mathrm{H}_{2} \mathrm{O}_{2}(\mathrm{aq})\right]}{d t}=A_{\mathrm{UO}_{2}} \cdot k_{\text {rad }}
$$

where $\left[\mathrm{H}_{2} \mathrm{O}_{2}(\mathrm{aq})\right]$ is the concentration of $\mathrm{H}_{2} \mathrm{O}_{2}$ in solution (mol. $\mathrm{L}^{-1}$ ), $\mathrm{A}_{\mathrm{UO}}$ is the volumetric surface of $\mathrm{UO}_{2}\left(\mathrm{~m}^{2} \cdot \mathrm{L}^{-1}\right)$, and $\mathrm{k}_{\text {rad }}$ is the intrinsic kinetic constant of $\mathrm{H}_{2} \mathrm{O}_{2}$ production $\left(\mathrm{mol} \cdot \mathrm{m}^{-2} \cdot \mathrm{s}^{-1}\right)$.

The alpha activity of $385 \mathrm{MBq} \cdot \mathrm{guor}^{-1}$ of the 50 -years $\mathrm{UO}_{2}$ pellets corresponds to an alpha dose rate of $4.7 \times 10^{-1} \mathrm{~J} \cdot \mathrm{kg}^{-1} \cdot \mathrm{s}^{-1}$. The constants $\mathrm{k}_{\mathrm{rad}}$ was estimated to be $2 \times 10^{-9} \mathrm{~mol} . \mathrm{m}^{-2} \cdot \mathrm{s}^{-1}$ considering that:

- the geometric surface of the pellets was $3 \mathrm{~cm}^{2}$ and the density $10.75 \mathrm{~g} . \mathrm{cm}^{-3}$;

only the alpha emitters present in a $12 \mu \mathrm{m}$ thick $\mathrm{UO}_{2}$ surface layer (range for $5 \mathrm{Mev}$ alpha particles in $\mathrm{UO}_{2}$ ) contribute to irradiating the solution and therefore to producing $\mathrm{H}_{2} \mathrm{O}_{2}$;

- the alpha primary yield is $0.98 \mathrm{H}_{2} \mathrm{O}_{2}$ molecule/ $100 \mathrm{eV}$; 
- the Avogadro constant, $\mathrm{N}_{\mathrm{A}}=6.022 \times 10^{23}$ molecules. $\mathrm{mol}^{-1}$.

This constant, which overestimates $\mathrm{H}_{2} \mathrm{O}_{2}$ production, was initially introduced in the model. The model was then calibrated using the results of $\mathrm{UO}_{2}$ leaching experiments conducted in carbonated water by Muzeau et al. (2009). The constant was lowered to $7 \times 10^{-10} \mathrm{~mol} \cdot \mathrm{m}^{-2} \cdot \mathrm{s}^{-1}$ to correctly fit the experimental values.

\subsubsection{Kinetics of $\mathrm{UO}_{2}$ matrix dissolution}

In this study, the alteration of $\mathrm{UO}_{2}$ could have resulted from two processes:

- the intrinsic dissolution of $\mathrm{UO}_{2}$ under reducing conditions;

- the oxidative dissolution of $\mathrm{UO}_{2}$ induced by the presence of oxidative species, mainly $\mathrm{H}_{2} \mathrm{O}_{2}(\mathrm{aq})$ which is the most important alpha radiolytic oxidant for $\mathrm{UO}_{2}$ oxidative dissolution (Ekeroth et al., 2006; Lousada et al., 2013).

\subsubsection{Under reducing conditions}

The intrinsic dissolution of $\mathrm{UO}_{2}$ under reducing conditions corresponds to the chemical reaction:

$$
\mathrm{UO}_{2}+2 \mathrm{H}_{2} \mathrm{O} \Leftrightarrow \mathrm{U}(\mathrm{OH})_{4}
$$

The kinetic rate of this reaction is expressed as follows:

$$
R_{\text {red }}=\frac{d\left[\mathrm{UO}_{2}\right]}{d t}=A_{\mathrm{UO}_{2}} \cdot k_{\text {red }} \cdot\left(\frac{I A P}{K_{U O_{2}}}-1\right)
$$

with $\left[\mathrm{UO}_{2}\right]$ being the concentration of the mineral $\mathrm{UO}_{2}\left(\mathrm{~mol}^{-1} \mathrm{~L}^{-1}\right), \mathrm{A}_{\mathrm{UO} 2}$ the volumetric surface of $\mathrm{UO}_{2}$ $\left(\mathrm{m}^{2} \cdot \mathrm{L}^{-1}\right), \mathrm{k}_{\text {red }}$ the intrinsic kinetic rate constant of $\mathrm{UO}_{2}$ dissolution under reducing conditions (mol. $\mathrm{m}^{-}$ ${ }^{2} . s^{-1}$ ), IAP the ionic activity product (no unit), and $\mathrm{K}_{\mathrm{UO} 2}$ the dissociation thermodynamic equilibrium constant of the reaction (no unit).

A rate constant value of $2 \times 10^{-12} \mathrm{~mol} \cdot \mathrm{m}^{-2} \cdot \mathrm{s}^{-1}$ was taken from the literature. Bruno et al. (1991) gave a dissolution rate of $\mathrm{UO}_{2}$ under reducing conditions of $1.9 \times 10^{-12} \mathrm{~mol} \cdot \mathrm{m}^{-2} \cdot \mathrm{s}^{-1}$ for $7 \leq \mathrm{pH} \leq 11$, and Ulrich et al. (2008) gave a similar value of $2 \times 10^{-12} \mathrm{~mol} \cdot \mathrm{m}^{-2} \cdot \mathrm{s}^{-1}$ for $3 \leq \mathrm{pH} \leq 8$. Both studies were carried out in $\mathrm{pH}$ ranges representative of the $\mathrm{pH}$ measured in our leaching experiments $(\mathrm{pH} \sim 7)$.

\subsubsection{Under oxidizing conditions}

The oxidative dissolution of $\mathrm{UO}_{2}$ in presence of hydrogen peroxide can be written as:

$$
\mathrm{UO}_{2}+2 \mathrm{H}^{+}+\mathrm{H}_{2} \mathrm{O}_{2} \rightarrow \mathrm{UO}_{2}^{2+}+2 \mathrm{H}_{2} \mathrm{O}
$$

The kinetic rate of the $\mathrm{UO}_{2}$ oxidative dissolution used in the model is represented by the following equation:

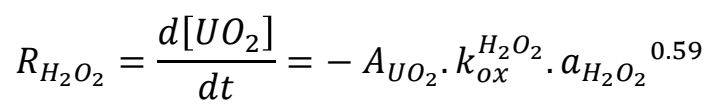

where $A_{\mathrm{UO} 2}$ is the volumetric surface of $\mathrm{UO}_{2}\left(\mathrm{~m}^{2} \cdot \mathrm{L}^{-1}\right), \mathrm{k}_{\mathrm{ox}}{ }^{\mathrm{H} 2 \mathrm{O}}$ is the intrinsic kinetic constant of $\mathrm{UO}_{2}$ dissolution in the presence of the oxidizing species $\mathrm{H}_{2} \mathrm{O}_{2}\left(\mathrm{~mol} \cdot \mathrm{m}^{-2} \cdot \mathrm{s}^{-1}\right)$, $\mathrm{a}_{\mathrm{H} 2 \mathrm{O} \text { (aq) }}$ is the activity of $\mathrm{H}_{2} \mathrm{O}_{2}$ in solution (no unit).

This equation was adapted from the dissolution law given by Merino et al. (Merino et al., 2005) based on the leaching of synthetic $\mathrm{UO}_{2}$ powder under $\mathrm{N}_{2}$ bubbling in carbonated water $\left(\left[\mathrm{HCO}_{3}{ }^{-}\right]=\right.$ $2 \times 10^{-3} \mathrm{M}$, representative of the COx synthetic water): 


$$
\log (k)=0.59 \log \left[\mathrm{H}_{2} \mathrm{O}_{2}\right]-6.2 \quad \text { i.e. } \quad k\left(\mathrm{~mol} . \mathrm{m}^{-2} \cdot \mathrm{s}^{-1}\right)=6 \times 10^{-7}\left[\mathrm{H}_{2} \mathrm{O}_{2}\right]^{0.59}
$$

The constant $\mathrm{k}_{\mathrm{ox}}{ }^{\mathrm{H} O 2}$ was rounded up to $10^{-6} \mathrm{~mol} \cdot \mathrm{m}^{-2} \cdot \mathrm{s}^{-1}$ and the exponent of 0.59 was kept.

\subsubsection{Kinetics of anoxic iron corrosion}

The corrosion of metallic iron $\left(\mathrm{Fe}^{0}\right)$ in anoxic media can be written as:

$$
\mathrm{Fe}^{0}+2 \mathrm{H}_{2} \mathrm{O} \rightarrow \mathrm{Fe}^{2+}+2 \mathrm{OH}^{-}+\mathrm{H}_{2}
$$

A kinetic constraint was imposed on this corrosion process using the following law:

$$
\frac{d[F e]}{d t}=-k_{\text {anox }} \cdot A_{F e}
$$

where $[\mathrm{Fe}]$ is the concentration of metallic iron $\left(\mathrm{mol}^{-\mathrm{L}^{-1}}\right), \mathrm{k}_{\text {anox }}$ is the intrinsic kinetic rate constant of iron corrosion under anoxic conditions $\left(\mathrm{mol} . \mathrm{m}^{-2} \cdot \mathrm{s}^{-1}\right), \mathrm{A}_{\mathrm{Fe}}$ is the volumetric surface of iron $\left(\mathrm{m}^{2} . \mathrm{L}^{-1}\right)$. De Combarrieu et al. (De Combarrieu et al., 2007) found a rate of $6 \times 10^{-9} \mathrm{~mol} \cdot \mathrm{m}^{-2} \cdot \mathrm{s}^{-1}$ for the dissolution of metallic iron in synthetic $\mathrm{COx}$ water at $90^{\circ} \mathrm{C}$ and in the presence of clay introduced as a powder in the reactor. This kinetic rate constant $k_{\text {anox }}$ was lowered to $3 \times 10^{-9} \mathrm{~mol} \cdot \mathrm{m}^{-2} \cdot \mathrm{s}^{-1}$ by fitting the Fe aqueous concentration in a pre-corrosion experiment of the iron foil carried out in the synthetic COx water at $25^{\circ} \mathrm{C}$. This slight decrease with temperature is consistent with the low activation energy of iron corrosion, about $15 \mathrm{~kJ} . \mathrm{mol}^{-1}$.

\section{Experimental results}

\subsection{Solution analyses}

\subsubsection{COx water chemistry}

For both 10000-years $\mathrm{UO}_{2}$ and 50-years $\mathrm{UO}_{2}$ leaching experiments in $\mathrm{COx}$ water in the presence of iron, none of the $\mathrm{COx}$ water constituents $\left(\mathrm{K}, \mathrm{Na}, \mathrm{Ca}, \mathrm{Mg}, \mathrm{Sr}, \mathrm{Si}, \mathrm{Cl}^{-}, \mathrm{SO}_{4}{ }^{2-}\right.$ ) showed a significant variation in concentration due to the high solution to solid ratio of the experiments. The $\mathrm{pH}$ was between $6.5( \pm 0.1)$ and $8.0( \pm 0.1)$ and showed no clear variation throughout the leaching tests. There was no noticeable difference between the measurements carried out in-situ or ex-situ. On the contrary, the redox potential Eh showed a significant difference between the in-situ and ex-situ measurements. When measured ex-situ, Eh was only slightly reducing with values between $50( \pm 10)$ $\mathrm{mV} / \mathrm{SHE}$ and $-100( \pm 10) \mathrm{mV} / \mathrm{SHE}$. However, it dropped to a greater reducing value when measured directly in-situ: between $-100( \pm 10)$ and $-300( \pm 10) \mathrm{mV} / \mathrm{SHE}$. The in-situ Eh measurements are more representative and such reducing values were due to the presence of the iron foils. As it corrodes, iron foil releases redox active species $\left(\mathrm{Fe}^{2+}\right.$ and $\left.\mathrm{H}_{2}\right)$ that create reducing conditions within the homogeneous solution. It must be specified that this redox potential measurement nevertheless remains only indicative and qualitative. Firstly the in-situ measurement, which was done directly in the reactor at the end of the experiment, required the device to be opened inside the glove box. This means that the hydrogen present in the system may well have dispersed and that during the experiment, in a closed system, the potential was in fact lower. Moreover it has been shown that the measurement of the potential is the presence of hydrogen and of platinum may lead to local negative potentials through local activation processes, limiting the range of such a measurement (Spahiu et al., 2000).

\subsubsection{Uranium concentrations}




\section{[FIGURE 1]}

[FIGURE 2]

Fig. 1 and 2 show the evolution of uranium concentrations for 50 -years $\mathrm{UO}_{2}$ and 10000 -years $\mathrm{UO}_{2}$ leaching tests respectively. For both types of samples, the experiments were performed in increasingly complex leaching media: 1) in carbonated water (Muzeau et al., 2009), 2) in synthetic COx water, 3 ) in synthetic COx water in the presence of iron.

The results of Ref $\mathrm{UO}_{2}$ leaching in synthetic $\mathrm{COx}$ water are also reported in the graphs (Fig. 1 and 2). The leaching of Ref $\mathrm{UO}_{2}$ pellets in synthetic $\mathrm{COx}$ water led to very low concentration of uranium in solution, around 0.2-1.0 $\mu \mathrm{g} . \mathrm{L}^{-1}$, not far from the solubility limit of $\mathrm{UO}_{2} \bullet \mathrm{xH}_{2} \mathrm{O}(\mathrm{am})\left(0.1 \mu \mathrm{g} . \mathrm{L}^{-1}\right)$. These $\mathrm{UO}_{2}$ pellets had no alpha activity, and so they did not induce alpha radiolysis of water. The $\mathrm{UO}_{2}$ matrix was therefore not submitted to oxidative dissolution by radiolytic species and the uranium in solution was $\mathrm{U}(\mathrm{IV})$ in equilibrium with $\mathrm{UO}_{2} \bullet \mathrm{xH}_{2} \mathrm{O}(\mathrm{am})$.

Figure 1 illustrates the influence of the environmental conditions on the uranium concentrations for the most radioactive $\mathrm{UO}_{2}$ sample. The leaching of 50-years $\mathrm{UO}_{2}$ in carbonated water led to a fast increase in the concentration of uranium in solution, due to the oxidative dissolution of the $\mathrm{UO}_{2}$ pellets (Muzeau et al., 2009), as the alpha activity of these pellets (385 MBq.g Ooo $^{-1}$ ) induced the radiolysis of water and the production of oxidizing species. When 50 -years $\mathrm{UO}_{2}$ pellets were leached in synthetic COx water, the concentration of uranium in solution still increased with time (up to 10 $\mu \mathrm{g} . \mathrm{L}^{-1}$ in one year) but more slowly than in carbonated water. In this case oxidative dissolution occurred, but seems to be inhibited. Finally, in the presence of an iron foil, the concentration of uranium dropped to values lower than $1.0 \mu \mathrm{g} \cdot \mathrm{L}^{-1}$ and close to the concentrations of uranium obtained during the leaching of Ref $\mathrm{UO}_{2}$. Moreover, after filtration and ultra-filtration (sample at 427 days), the concentration of uranium reached the $\mathrm{UO}_{2} \bullet \mathrm{xH}_{2} \mathrm{O}(\mathrm{am})$ solubility limit at $0.1 \mu \mathrm{g} . \mathrm{L}^{-1}$. This indicates the presence of $U(I V)$ in solution, unlike the leaching experiments in carbonated water and in synthetic COx water.

To quantify the total amount of uranium released in the presence of the iron foil, the distribution of uranium between the different parts of the system was estimated thanks to acidic rinses (Fig. 3 a) at the end of the leaching tests. The solution actually contained only $0.1 \%$ of the total amount of uranium released $(0.01 \mu \mathrm{g})$. An intermediate fraction of $23.8 \%$ was found on the iron foil $(2.4 \mu \mathrm{g})$. The majority of the released uranium was found in the colloidal/sorbed/precipitated fraction $(76.1 \%$ i.e. $7.60 \mu \mathrm{g})$. However, these quantities can be predominantly attributed to sorption or precipitation on the $\mathrm{TiO}_{2}$ reactor, given the small decrease in the concentration of uranium in solution after filtration and ultra-filtration. In total, only $10 \mu \mathrm{g}$ of uranium were released in the presence of metallic iron after more than one year of leaching.

In the leaching experiments for 10000-years $\mathrm{UO}_{2}$, the concentrations of uranium in solution were always very low whatever the leaching media: carbonated water (Muzeau et al., 2009), COx water, and COx water in the presence of an iron foil. The values range between $0.1 \mu \mathrm{g} \cdot \mathrm{L}^{-1}$ and $1 \mu \mathrm{g} . \mathrm{L}^{-1}$, and are similar to those from the reference $\mathrm{UO}_{2}$ leaching experiment. They are also close to the $\mathrm{UO}_{2} \bullet \mathrm{xH}_{2} \mathrm{O}(\mathrm{am})$ solubility limit. The distribution of uranium at the end of the experiment (Fig. $3 \mathrm{~b}$ ) in the presence of iron reveals that a total of only $1.8 \mu \mathrm{g}$ of uranium was released during the experiment, found predominantly on the $\mathrm{TiO}_{2}$ surface (70\%). 
For the two batches of doped $\mathrm{UO}_{2}$ studied, the presence of iron led to very low concentrations and total quantities of uranium released. Their behaviors were similar, with no significant differences compared to the reference batch, $\mathrm{Ref} \mathrm{UO}_{2}$.

\section{[FIGURE 3]}

\subsubsection{Iron concentrations}

The evolutions of Fe concentrations in solution for the three experiments containing an iron foil are reported in Fig. 4. For all of the experiments, the Fe concentrations increased fairly linearly at the beginning, revealing that the corrosion of the iron foils occurred. This was also confirmed by the presence of $\mathrm{H}_{2}(\mathrm{~g})$ at the end of the experiments: $4780 \mathrm{ppm}$ of $\mathrm{H}_{2}(\mathrm{~g})$ in the 10000-years $\mathrm{UO}_{2}$ experiment, $4250 \mathrm{ppm}$ of $\mathrm{H}_{2}(\mathrm{~g})$ in the 50 -years $\mathrm{UO}_{2}$ experiment, and $1050 \mathrm{ppm}$ of $\mathrm{H}_{2}(\mathrm{~g})$ in the blank experiment. After over 200-300 days, the Fe concentrations seemed to reach a plateau at around 75 $\mathrm{mg} \cdot \mathrm{L}^{-1}$ in the 10000 -years $\mathrm{UO}_{2}$ experiment, $60 \mathrm{mg} \cdot \mathrm{L}^{-1}$ in the 50 -years $\mathrm{UO}_{2}$ experiment, and $25 \mathrm{mg} . \mathrm{L}^{-1}$ in the blank experiment. This indicates the precipitation of Fe-secondary phases. Their nature was investigated by surface characterization methods.

\section{[FIGURE 4]}

\subsection{Surface characterization}

\subsubsection{On the $\mathrm{UO}_{2}$ pellets}

SEM micrographs acquired on a 50-years $\mathrm{UO}_{2}$ pellet leached in $\mathrm{COx}$ water in the presence of iron revealed that the surface of the pellet was completely covered by a precipitate around $20 \mu \mathrm{m}$ thick (Fig. 5 a, b). This phase was actually composed of two layers:

- The first layer, directly in contact with $\mathrm{UO}_{2}$, was about $8 \mu \mathrm{m}$ thick and seemed rather amorphous. Its composition was around 20 at. \% Si and 80 at. \% Fe (average of EDX analyses on 5 different areas) (Fig. 6 a, b).

- Above this, a $12 \mu \mathrm{m}$ thick layer was composed of triangular-shaped precipitates. They contained only 5 at. \% Si and 95 at. \% Fe (average of EDX analyses on 7 different areas) (fig. 6 a, c).

The 10000-years $\mathrm{UO}_{2}$ pellet leached in the same conditions (COx water and iron foil) was not completely covered with the precipitate observed on the 50 -years $\mathrm{UO}_{2}$ (Fig. $5 \mathrm{c}$ ). Some triangleshaped precipitates previously observed on the 50-years $\mathrm{UO}_{2}$ were also present on the 10000 -years $\mathrm{UO}_{2}$ pellet, but in a smaller more scattered quantity (Fig $5 \mathrm{~d}$ ). EDX analyses realized on these precipitates (Fig. 6 d, e) revealed a composition of 96 at. \% Fe and 4 at. \% Si (average of EDX analyses on 8 different areas), very close to the composition of the precipitates observed on the 50 -years $\cup_{2}$. Sometimes, traces of $\mathrm{Cl}$ were also present.

\section{[FIGURE 5]}

\section{[FIGURE 6]}

Raman spectroscopy was performed on these secondary phases to determinate their nature. Raman spectra acquired on the triangle-shaped precipitates from both 10000 -years $\mathrm{UO}_{2}$ and 50 -years $\mathrm{UO}_{2}$, and on the amorphous crust from the 50 -years $\mathrm{UO}_{2}$, are displayed in Fig. 7. They were compared to the spectrum of akaganeite $(\beta-\mathrm{FeOOH})$ proposed by Neff (Neff, 2003). The three experimental 
spectra of the study described here were very similar and showed a good correspondence to the spectrum of the Fe(III)-hydroxide, in particular for the peaks at 311, 390, 722 and $1395 \mathrm{~cm}^{-1}$.

A sensitivity study showed that the precipitates could be oxidized under a laser beam. At $1.1 \mathrm{~mW}$, the experimental spectrum obtained on the sticks is similar to that of maghemite $\left(\gamma-\mathrm{Fe}_{2} \mathrm{O}_{3}\right)$ from Sousa et al. (Sousa et al., 2001). After receiving a power of $5.9 \mathrm{~mW}$, the spectrum of the triangleshaped precipitate became identical to that of hematite $\left(\alpha-\mathrm{Fe}_{2} \mathrm{O}_{3}\right)$ given by Neff (Neff, 2003). The phase transformation of $\mathrm{FeO}(\mathrm{OH})$ to $\alpha-\mathrm{Fe}_{2} \mathrm{O}_{3}$ has already been observed in the literature (de Faria and Lopes, 2007) which supports the idea that the precipitates observed on the $\mathrm{UO}_{2}$ pellets are akaganeite-type Fe(III)-hydroxides.

However, EDX analyses revealed the presence of silicon in the precipitates which was not detected by Raman spectroscopy. The precipitation of a phase like cronstedtite $\mathrm{Fe}^{2+}{ }_{2} \mathrm{Fe}^{3+}\left(\mathrm{Si}_{1} \mathrm{Fe}^{3+} \mathrm{O}_{5}\right)(\mathrm{OH})_{4}$ is not to be excluded, and its molar ratio would be in good agreement with the composition 20 at. \% Si-80 at. \% Fe obtained by EDX on the amorphous layer from the 50 -years $\mathrm{UO}_{2}$ pellet.

\section{[FIGURE 7]}

\subsubsection{On the iron foils}

SEM micrographs showed that both the iron foils corroded in the 50-years $\mathrm{UO}_{2}$ and the 10000 -years $\mathrm{UO}_{2}$ experiments were scattered with different secondary phases (Fig. 8). Raman spectroscopy was also performed on these precipitates to determine their nature (Fig. 9).

Iron foil from the 50-years $\mathrm{UO}_{2}$ experiment

Three different kinds of precipitates were present on the iron foil corroded in COx water: 1) needleshaped precipitates (Fig. 8 a), 2) layer-shaped precipitates (Fig. 8 b) and 3) nano-spheres (Fig. 8 C).

1) The needle-shaped precipitates (fig. 8 a) were the most common on the iron foil. They were composed of around 98 at. \% of $\mathrm{Ca}$ and 2 at. \% of Sr (average of EDX analyses on 12 different areas). A fraction of $\mathrm{Fe}$ in the same proportion as $\mathrm{Sr}$ was also detected, but could have come from the iron foil below the precipitate. The typical Raman spectrum obtained on these precipitates (Fig. 9 a) shows a peak at $1084 \mathrm{~cm}^{-1}$ and three smaller ones at 150, 204 and $703 \mathrm{~cm}^{-1}$. This spectrum is identical to that for aragonite from the RRUFF database, displaying peaks at 151, 205, 702 and 1085 $\mathrm{cm}^{-1}$ (RRUFF online database, ID number R080142). The strontianite spectrum (RRUFF online database, ID number R050476) is so similar to that of aragonite that it is difficult to distinguish the contribution of the small amount of $\mathrm{Sr}$ in the needle-shaped mineral Raman spectrum. However, two peaks around 180 and $250 \mathrm{~cm}^{-1}$ may be associated with strontianite. Moreover among calcium carbonates, the needle form has already been observed in the literature for aragonite (Mavromatis et al., 2015; Lee et al., 2015). Needle-shaped precipitates are thus considered as a solid-solution of Sr-aragonite, $\left(\mathrm{Ca}_{0.98}, \mathrm{Sr}_{0.02}\right) \mathrm{CO}_{3}$.

2) The layer-shaped secondary phase (Fig. 8 b) was composed of around 80 at. \% Fe and 20 at. \% Ca (average of EDX analyses on 7 different areas). A part of the Fe signal could have come from the iron foil below the precipitate, but the mineral seemed thick enough to minimize this phenomenon. The Raman spectrum of this phase is given in Fig. 9 c, and displays a peak at $1084 \mathrm{~cm}^{-1}$ and a smaller one at $277 \mathrm{~cm}^{-1}$. Two other little bumps could be present at 175 and $727 \mathrm{~cm}^{-1}$. This spectra is in good agreement with that for ankerite $\left(\mathrm{CaFe}^{\prime \prime}\left(\mathrm{CO}_{3}\right)_{2}\right)$ given by Schlegel et al. (Schlegel et al., 2014), that presents two peaks at 281 and $1084 \mathrm{~cm}^{-1}$. Calcite $\left(\mathrm{CaCO}_{3}\right)$ Raman spectrum also shows the peaks at 
280 and $1086 \mathrm{~cm}^{-1}$, but the small peaks at 206 and $703 \mathrm{~cm}^{-1}$ do not fit our spectrum (RRUFF online database, ID number R050128). Taking this and the EDX composition into account, the Ca-Fe secondary phase ankerite seems more likely.

3) The nano-spheres (Fig. 8 c) had a silicon-based composition (EDX analyses on 2 areas). Unfortunately, the resolution of the optical microscope coupled to the Raman spectrometer did not allow for the detection and characterization of these precipitates. However, amorphous nano-silica seems to be the best hypothesis.

Traces of uranium ( $\leq 1$ at. \%) were rarely detected (4 times over 73 EDX analyses) and always were associated with the other elements from the COx water in variable quantities. They probably came from the drying of leaching water droplets rather than a U-secondary phase precipitation.

Iron foil from the 10000-years $\mathrm{UO}_{2}$ experiment

Three different types of secondary phases were also found on this iron foil: 1) needle-shaped precipitates, 2) ball-shaped precipitates and 3) a crackled crust. However, some of them were not identical to those observed in the 50 -years $\mathrm{UO}_{2}$ experiment.

1) The needle-shaped precipitates (Fig. 8 e) were identical to those observed in the 50 -years $\mathrm{UO}_{2}$ experiment (Fig. 8 a). Their needle form was very similar, as well as their composition of $~ 98$ at. \% Ca and $\sim 2$ at. \% Sr (average of EDX analyses on 11 different areas). The Raman spectrum (Fig. 9 b) was also identical to that obtained on $\mathrm{Sr}$-aragonite from the 50 -years $\mathrm{UO}_{2}$ experiment (Fig. 9 a), indicating a solid solution of $\mathrm{Sr}$-aragonite, $\left(\mathrm{Ca}_{0.98}, \mathrm{Sr}_{0.02}\right) \mathrm{CO}_{3}$.

2) Ball-shaped precipitates were only found in the 10000-years experiment (Fig. 8 e). They were predominantly composed of iron ( $\sim 96$ at. \% Fe) with traces of calcium ( 4 at. \% Ca) (average of EDX analyses on 8 different areas). The Raman spectrum of this precipitate displayed a single peak at $1072 \mathrm{~cm}^{-1}$ (Fig. 9 d) which, based on the EDX analyses and Raman literature data (Saheb et al., 2008; Romaine et al., 2013), may be attributed to chukanovite $\mathrm{Fe}_{2}(\mathrm{OH})_{2}\left(\mathrm{CO}_{3}\right)$. Moreover, SEM micrographs of chukanovite from the literature (Pandarinathan et al., 2014) show a very similar microstructure to that of our experimental precipitates.

3) The last type of precipitate was a crackled crust, composed mainly of silicon (EDX analyses on 12 different areas) (Fig. 8 f). Raman spectroscopy performed on this phase was not conclusive. This suggests amorphous silica precipitation but with a different microstructure compared to the silica nano-spheres from the 50 -years $\mathrm{UO}_{2}$ experiment (Fig. $8 \mathrm{c}$ ).

[FIGURE 8]

[FIGURE 9]

\subsection{Discussion and modeling}

\subsubsection{Initial state of the modeled system}

The 50-years $\mathrm{UO}_{2}$ leaching experiment in $\mathrm{COx}$ water in the presence of iron was submitted to reactive transport modeling using the HYTEC code and the model described in section 3 . The simulation grid representing the experimental setup is given in Fig. 11 a. Half of the real reactor containing the solution, the iron foil and the two Pu-doped $\mathrm{UO}_{2}$ pellets was represented in $2 \mathrm{D}$, but the calculation was performed for the entire reactor via a circular revolution around the $y$-axis. The experimental surfaces and masses of the $\mathrm{UO}_{2}$ pellets and the iron foil were conserved. 
The alpha activity of the 50 -years $\mathrm{UO}_{2}$ pellets induced the production of $\mathrm{H}_{2} \mathrm{O}_{2}(\mathrm{aq})$ by alpha radiolysis of water in a $40 \mu \mathrm{m}$ thick layer around the $\mathrm{UO}_{2}$ pellets (corresponding to alpha particle path distance in water). In the model, this phenomenon was represented by the generation of $\mathrm{H}_{2} \mathrm{O}_{2}(\mathrm{aq})$ at the surface of the $\mathrm{UO}_{2}$ pellets (kinetics detailed in section 3.2.1). Without considering any pre-corrosion step of the iron foil, Fig. 10 a shows the production of $\mathrm{H}_{2} \mathrm{O}_{2}$ after 5 hours induced by the alpha irradiation of the 50-years $\mathrm{UO}_{2}$ : a plume of $\mathrm{H}_{2} \mathrm{O}_{2}$ forms around the two $\mathrm{UO}_{2}$ pellets and slowly diffuses towards the bulk solution. $\mathrm{H}_{2} \mathrm{O}_{2}$ leads to the release of uranium in solution (Fig. $10 \mathrm{~b}$ ) at a relatively high concentration $\left(\approx 10^{-6} \mathrm{~mol} \cdot \mathrm{L}^{-1}\right)$ due to the oxidative kinetic dissolution of the $\mathrm{UO}_{2}$ pellets according to Eqs. 4 and 5. Simultaneously to the generation of $\mathrm{H}_{2} \mathrm{O}_{2}(\mathrm{aq})$, Fig. $10 \mathrm{c}$ shows a local increase of $\mathrm{Fe}(\mathrm{II})$ in solution due to the iron foil anoxic corrosion (Eqs. 7 and 8). The plume of Fe(II) slowly diffuses in the bulk solution towards the pellets. Progressively, there is a scavenging of $\mathrm{H}_{2} \mathrm{O}_{2}$ in the homogeneous solution by dissolved $\mathrm{Fe}(\mathrm{II})$ species (mostly $\mathrm{Fe}^{2+}$, but also $\mathrm{FeCO}_{3} \ldots$ in the $\mathrm{COx}$ water):

$$
\frac{1}{2} \mathrm{H}_{2} \mathrm{O}_{2}+\mathrm{Fe}^{2+} \rightarrow \mathrm{Fe}^{3+}+\mathrm{OH}^{-}
$$

The solution is almost depleted in $\mathrm{H}_{2} \mathrm{O}_{2}$ after 30 hours, and totally after 72 hours. The oxidative dissolution of the $\mathrm{UO}_{2}$ is stopped (and the uranium concentration decreases due to $\mathrm{Fe}(\mathrm{II})$ reduction in the modeling). The coupling between the different chemical reactions and diffusion is well illustrated by this modeling scenario. However, a pre-corrosion step was set in the experiments. While considering this process in the modeling, there is an initial content in $\mathrm{Fe}(\mathrm{II})$ of about $5 \times 10^{-5} \mathrm{~mol}^{-\mathrm{L}^{-1}}$ in the whole solution (Fig. $10 \mathrm{f}$ ) and siderite deposited on the iron foil since the beginning. $\mathrm{H}_{2} \mathrm{O}_{2}(\mathrm{aq}$ ) is readily consumed by Fe(II), as shown in Fig. $10 \mathrm{~d}$. In parallel, Fig. $10 \mathrm{f}$ shows a depletion of $10^{-5} \mathrm{~mol}^{-\mathrm{L}^{-1}}$ of the Fe(II) background concentration. The uranium concentration is now three orders of magnitude lower $\left(\approx 10^{-9}\right.$ mol. $\mathrm{L}^{-1}$, Fig. 10 e) and is controlled by $\mathrm{UO}_{2}$ dissolution under reducing condition according to Eq. 3. The pre-corrosion step was assumed in all the modeling results discussed hereafter.

\section{[FIGURE 10]}

\subsubsection{Precipitation of $\mathrm{Fe}(\mathrm{III})$-hydroxide on $\mathrm{UO}_{2}$ and dissolution of the $\mathrm{UO}_{2}$ pellets}

The model predicts the precipitation of the $\mathrm{Fe}(\mathrm{III})$ oxi-hydroxide mineral called goethite (FeOOH) onto the $\mathrm{UO}_{2}$ pellets (Fig. $11 \mathrm{~b}$ ), which is consistent with the precipitation of akaganeite (FeOOH) observed in the experiment. To our knowledge, there is no thermodynamic constant of akaganeite formation available in the literature. Goethite is a more thermodynamically stable polymorph of akaganeite. However, akaganeite has been reported to form preferentially over goethite in solutions with high chloride concentrations (Remazeilles and Refait, 2007), which is the case for the synthetic cOx water.

The mineral goethite is composed of $\mathrm{Fe}(\mathrm{III})$ whereas the iron foil corrosion produces $\mathrm{Fe}(\mathrm{II})$ in solution. A redox reaction is thus needed to transform $\mathrm{Fe}^{2+}$ into $\mathrm{Fe}^{3+}$. Moreover, $\mathrm{Fe}^{3+}$ is very insoluble at $\mathrm{pH}$, and precipitated immediately on the $\mathrm{UO}_{2}$ surface:

$$
\mathrm{Fe}^{3+}+2 \mathrm{H}_{2} \mathrm{O} \rightarrow \mathrm{FeOOH}(\mathrm{s})+3 \mathrm{H}^{+}
$$

At this place, the strong oxidant $\mathrm{H}_{2} \mathrm{O}_{2}(\mathrm{aq})$ that should appear has completely vanished, so a redox reaction between $\mathrm{Fe}^{2+}$ and $\mathrm{H}_{2} \mathrm{O}_{2}$ (Eq. 9) explains both the $\mathrm{Fe}(\mathrm{III})$-mineral precipitation and the $\mathrm{H}_{2} \mathrm{O}_{2}$ consumption. 
The $\mathrm{H}_{2} \mathrm{O}_{2}$ consumed for the precipitation of $\mathrm{Fe}(\mathrm{III})$-hydroxide is not available for the oxidative dissolution of $\mathrm{UO}_{2}$, so the oxidative dissolution of $\mathrm{UO}_{2}$ could be stopped in the presence of metallic iron. Fig. $11 \mathrm{c}$ shows that the precipitation of $\mathrm{UO}_{2} \bullet \mathrm{xH}_{2} \mathrm{O}(\mathrm{am})$ occurs in the absence of oxidative dissolution. The steady state concentration of uranium in solution predicted by the model is $4 \times 10^{-10}$ mol. $\mathrm{L}^{-1}\left(0.1\right.$ ug. $\left.\mathrm{L}^{-1}\right)$ at $\mathrm{pH} 7.5$, in agreement with the measured aqueous concentrations.

Eventually, Fig. $11 \mathrm{~d}$ shows the sensitivity of the model with respect to the intensity of the alpha radiolysis. A ten-fold increase of $\mathrm{H}_{2} \mathrm{O}_{2}$ production (Eq. 1) leads to the shift of the redox front between $\mathrm{H}_{2} \mathrm{O}_{2}$ and $\mathrm{Fe}(\mathrm{II})$, and the subsequent precipitation of $\mathrm{FeOOH}$, from the pellet surfaces into the solution. The total amount of $\mathrm{FeOOH}$ is also higher compared to the reference case.

\section{[FIGURE 11]}

\subsubsection{How does the oxidative dissolution occur in the presence of iron?}

In the case of 50-years $\mathrm{UO}_{2}$ leaching in synthetic $\mathrm{COx}$ water in the presence of iron, uranium concentrations in solution were very low $\left(0.1 \mu \mathrm{g} \cdot \mathrm{L}^{-1}\right.$ after ultrafiltration) and indicate an equilibrium with the $\mathrm{U}(\mathrm{IV})$-phase $\mathrm{UO}_{2} \bullet \mathrm{xH}_{2} \mathrm{O}(\mathrm{am})$. Two hypotheses may explain this result:

1) $\mathrm{UO}_{2}$ oxidative dissolution occurs, but the released $\mathrm{U}(\mathrm{VI})$ is then reduced into $\mathrm{U}(\mathrm{IV})$ on the surfaces or in the homogeneous solution, and finally sorbed or precipitated into $\mathrm{UO}_{2} \bullet \mathrm{xH}_{2} \mathrm{O}(\mathrm{am})$;

2) there is no oxidative dissolution of $\mathrm{UO}_{2}$ and an equilibrium with $\mathrm{UO}_{2} \bullet \mathrm{xH}_{2} \mathrm{O}(\mathrm{am})$ is established.

If $\mathrm{UO}_{2}$ oxidative dissolution occurs (hypothesis 1 ), $\mathrm{U}(\mathrm{VI})$ must be released and then reduced into $\mathrm{U}(\mathrm{IV})$ by $\mathrm{Fe}(\mathrm{II})$ somewhere in the system, according to the following reaction:

$$
\mathrm{UO}_{2}^{2+}+2 \mathrm{Fe}^{2+}+2 \mathrm{H}_{2} \mathrm{O} \rightarrow U(\mathrm{OH})_{4}(\mathrm{aq})+2 \mathrm{Fe}^{3+}
$$

Some authors have indicated that reduction of $\mathrm{U}(\mathrm{VI})$ by $\mathrm{Fe}(\mathrm{II})$ in solution is thermodynamically possible (Du et al., 2011), but actually would not occur for kinetic reasons and would need to be catalyzed by a surface (Liger et al., 1999). In our system, the surfaces in contact with the solution were the iron foil, the $\mathrm{TiO}_{2}$ reactor walls, and the $\mathrm{UO}_{2}$ pellets.

The literature reports that $\mathrm{Fe}^{0}$ (Gu et al., 1998; Crane et al., 2015) as well as iron corrosion products (Grambow et al., 1996; Cui \& Spahiu, 2002; O'Loughlin et al., 2003) may reduce U(VI) into U(IV). On the contrary, the direct reduction of $\mathrm{U}(\mathrm{VI})$ onto $\mathrm{TiO}_{2}$ requires a photochemical reaction (Eliet and Bidoglio, 1998). However, some studies have shown that $\mathrm{Fe}(\mathrm{II})$ adsorbed onto $\mathrm{TiO}_{2}$ may act as a reducer (Zhu et al., 2013).

The presence of uranium on the iron foil and on the $\mathrm{TiO}_{2}$ reactor was investigated via surface characterization techniques (SEM-EDS, Raman spectroscopy) and acid rinses. A very low quantity of $U$ was found on the iron foil (only $2.4 \mu \mathrm{g}$ ). Most of the released $\mathrm{U}$ was sorbed or precipitated onto $\mathrm{TiO}_{2}$, but also represents a low quantity $(7.6 \mu \mathrm{g})$. Moreover, this quantity is compatible with direct sorption of $\mathrm{U}(\mathrm{IV})$ onto $\mathrm{TiO}_{2}$ without release of $\mathrm{U}(\mathrm{VI})$ by oxidative dissolution: the $\mathrm{TiO}_{2}$ reactor could act as a $\mathrm{U}(\mathrm{IV})$-pump until its sorption sites are saturated, the consumption of $\mathrm{U}(\mathrm{IV})$ being balanced by dissolution of $\mathrm{U}(\mathrm{IV})$ from equilibrium with $\mathrm{UO}_{2} \bullet \mathrm{H}_{2} \mathrm{O}(\mathrm{am})$. Latta et al. (Latta et al., 2014) studied the sorption of $\mathrm{U}(\mathrm{IV})$ onto $\mathrm{TiO}_{2}$ and gave a sorption capacity of 1 atom $\mathrm{U} / \mathrm{nm}^{2} \mathrm{TiO}_{2}$. Taking into account this capacity and the surface of the $\mathrm{TiO}_{2}$ reactor in contact with the leaching solution in the experiment described here $\left(\sim 150 \mathrm{~cm}^{2}\right)$, the quantity of $\mathrm{U}(\mathrm{VI})$ possibly sorbed would be $5.7 \mu \mathrm{g}$. This 
value is close to the quantity of $\mathrm{U}$ actually found on $\mathrm{TiO}_{2}$, so direct $\mathrm{U}(\mathrm{IV})$-sorption onto $\mathrm{TiO}_{2}$ could be the mechanism explaining the presence of $U$ on the reactor walls.

Concerning the surface of the $\mathrm{UO}_{2}$ pellets, no uranium was detected in the akaganeite precipitate covering the pellets. Moreover, the presence of $\mathrm{Fe}(\mathrm{III})$ was observed on the $\mathrm{UO}_{2}$ surface (akaganeite), and $\mathrm{Fe}(\mathrm{II})$ on the iron foil (ankerite) and in the solution (shown by the clear solution and the absence of colloids - Fig 4 shows no difference in the iron concentrations before and after ultrafiltration of the solution with a cut-off of $20 \mathrm{~nm}$ ). This indicates that the redox front was localized at the outermost surface of the $\mathrm{UO}_{2}$ pellets. The absence of uranium in the akaganeite precipitates also supports the modeling hypothesis that the homogeneous $\mathrm{H}_{2} \mathrm{O}_{2} / \mathrm{Fe}(\mathrm{II})$ reaction is sufficiently faster than the heterogeneous $\mathrm{H}_{2} \mathrm{O}_{2} / \mathrm{UO}_{2}$ reaction to be reasonably well modeled at thermodynamic equilibrium. It would mean that $\mathrm{H}_{2} \mathrm{O}_{2}$ did not oxidize the $\mathrm{UO}_{2}$ surface as soon as it was produced, probably due to the combination of this fast kinetics and the constant diffusive flux of Fe(II) from the solution very close to the surface.

At neutral $\mathrm{pH}$, the calculated dissolved concentration of $\mathrm{Fe}(\mathrm{II})$ controlled by siderite equilibrium was about $5 \times 10^{-5} \mathrm{~mol}^{-L^{-1}}$, while the measured concentrations during the pre-corrosion steps were within the range $1 \times 10^{-4}-4 \times 10^{-4}$ mol. $\mathrm{L}^{-1}$. These values were high enough to scavenge any effect of radiolytic oxidants on the $\mathrm{UO}_{2}$ matrix dissolution. The modeling results of Sec. 4.3.1 would indicate a minimum threshold of $10^{-5} \mathrm{~mol} / \mathrm{L}^{-1}$ in the present experiment. This threshold should be lower for less radioactive materials such as spent fuels after a few thousand years of disposal. The modeling underestimates $\mathrm{Fe}(\mathrm{II})$ concentration in solution for two main reasons. First, siderite was taken as a proxy for the corrosion products ankerite and chukanovite, the solubility of the latter being higher than the former. Secondly, the corrosion products were probably not at equilibrium with the solution. Generally speaking, siderite solubility is solution chemistry dependent. For instance, Cui et al. (2011) report an experimental values of $2 \times 10^{-5} \mathrm{~mol}^{-1} \mathrm{~L}^{-1}$ in their experiment with siderite and spent nuclear fuel. Magnetite is often considered as the long-term corrosion product of steel in performance assessment. Magnetite solubility is dependent on the $\mathrm{pH}$ and the redox potential, but a value around $10^{-5} \mathrm{~mol} . \mathrm{L}^{-1}$ can be considered as representative of many underground disposal formations of radioactive waste (e.g. Wersin et al., 2003).

Finally, only $10 \mu \mathrm{g}$ of uranium were released in total after 427 days. This is extremely low compared to the quantity of $U$ released by oxidative dissolution of 50 -years $\mathrm{UO}_{2}$ in carbonated water $(94.5 \mu \mathrm{g}$ in one month and more than $1000 \mu \mathrm{g}$ if the experimental data are extrapolated to one year).

A mass balance calculation was also carried out using HYTEC simulations for the 50 -years $\mathrm{UO}_{2}$ pellet experiment in COx synthetic water in presence of iron. Table 5 shows the quantities of uranium released and retrapped in a solid form for the two hypotheses envisaged concerning the influence of the dissolved ferrous ions on the dissolution mechanisms. In the two cases, the total concentration of uranium in solution was identical, and compatible with the formation of amorphous $\mathrm{UO}_{2} \cdot \mathrm{xH}_{2} \mathrm{O}$. However, the first hypothesis, corresponding to a release of $\mathrm{U}(\mathrm{VI})$ uranyl ions under the effect of $\mathrm{H}_{2} \mathrm{O}_{2}$ in solution immediately followed by a reduction by the ferrous ions, led to total quantities of released uranium much higher than those obtained experimentally. On the contrary, the second hypothesis, according to which $\mathrm{H}_{2} \mathrm{O}_{2}$ would be consumed on the surface by the ferrous ions and the oxidizing dissolution would thus be inhibited, led to quantities of released uranium which were compatible with the experimental mass balance data. 


\section{[TABLE 5]}

In addition to the two hypotheses envisaged at the beginning of this section, a protective effect from the precipitated iron hydroxide layer cannot be excluded. This layer, several microns thick, could possibly reduce the effects of water radiolysis by limiting the alpha particle path in the water at the surface and therefore the production of $\mathrm{H}_{2} \mathrm{O}_{2}$. Moreover, even if the ferrous ions clearly have a considerable impact on the alteration mechanisms, a contribution from hydrogen cannot be excluded provided it can be activated on the surface in presence of such precipitates and that the content in the system is high enough compared to the sample alpha activity. On the latter point, the hydrogen content in solution calculated based on the analysis of the gaseous atmosphere in the system studied here was $1 \times 10^{-5} \mathrm{~mol}^{-\mathrm{L}^{-1}}$. This concentration would be sufficient to inhibit the oxidizing dissolution of a fuel after 3000 years of aging (Carbol et al., 2009) and may therefore have contributed to reducing, even partially, the impact of oxidizers on a fuel after 50 years of alpha radioactive decay.

In conclusion, a significant oxidative dissolution of the 50 -years $\mathrm{UO}_{2}$ pellets leached in $\mathrm{COx}$ water in the presence of iron, followed by a reduction of released $\mathrm{U}(\mathrm{VI})$ into $\mathrm{U}(\mathrm{IV})$, was not demonstrated by the experimental results and the modeling. The hypothesis of an absence of, or a very low, oxidative dissolution is strongly favored.

In the case of the 10000 -years $\mathrm{UO}_{2}$ pellets, the concentrations of uranium were very low and close to the $\mathrm{UO}_{2} \bullet \mathrm{xH}_{2} \mathrm{O}(\mathrm{am})$ solubility limit whatever the leaching media: carbonated water (Muzeau et al., 2009), COx water, or COx water in the presence of iron. The total release of uranium estimated in the experiment in the presence of iron was also very low ( $<2 \mu \mathrm{g}$ in 280 days) and the precipitation of iron hydroxide was very limited, given the low alpha activity of the pellets. These results indicate that oxidative dissolution is ineffective for 10000 -years $\mathrm{UO}_{2}$ pellets. This is explained by a threshold in alpha activity observed in the literature, below which the alpha radiolysis of water does not induce oxidative dissolution (Poinssot et al. 2005).

\subsubsection{Precipitation of carbonated minerals on the iron foils}

Massive precipitations of Ca-based (Sr-aragonite) or Fe-based (ankerite, chukanovite) carbonated minerals were observed on the iron foils corroded in synthetic COx water. The modeling results of carbonated phase precipitations and $\mathrm{pH}$ evolutions at 450 days given in Fig. 12 enable an explanation of this phenomenon. The carbonated minerals calcite $\left(\mathrm{CaCO}_{3}\right)$ and siderite $\left(\mathrm{FeCO}_{3}\right)$ were used to create a simplified model, but it can be noted that ankerite, for example, is a solid solution between these two poles.

The modeling results indicated the precipitation of the carbonate-containing minerals, calcite (Fig. 12 a) and siderite (Fig. 12 b), onto the iron foil, in agreement with the experimental results. The model also predicted a slight increase in $\mathrm{pH}$ locally around the iron foil (Fig. $12 \mathrm{c}$ ), because its anoxic corrosion liberates hydroxide ions (Eq. 7). This local increase in $\mathrm{pH}$ shifts the carbonate equilibriums and favors the precipitation of carbonated minerals according to the following set of reactions:

$$
\begin{gathered}
\mathrm{HCO}_{3}^{-}+\mathrm{OH}^{-} \rightarrow \mathrm{CO}_{3}^{2-}+\mathrm{H}_{2} \mathrm{O} \\
\mathrm{Ca}^{2+}+\mathrm{CO}_{3}^{2-} \rightarrow \mathrm{CaCO}_{3} \\
\mathrm{Fe}^{2+}+\mathrm{CO}_{3}^{2-} \rightarrow \mathrm{FeCO}_{3}
\end{gathered}
$$


It is interesting to note that in the study described here, aragonite precipitated preferentially to its polymorph calcite, contrary to thermodynamic predictions. The literature reports that aragonite may be favored to calcite in the presence of high concentrations of $\mathrm{Mg}^{2+}$ (De Choudens-Sanchez and Gonzalez, 2009; Niedermayr et al., 2013; Boyd et al., 2014), which was the case in the synthetic COx water. Moreover Sr is known to co-precipitate with aragonite (e.g. Sunagawa et al., 2007), explaining its presence in the experimental calcium carbonate with a molar ratio of $x=0.02$.

\section{[FIGURE 12]}

\section{Conclusion}

In the context of spent nuclear fuel disposal in a geological repository, the effect of metallic iron (from containers) on the oxidative dissolution of the fuel was investigated in this study. Leaching experiments of alpha-doped $\mathrm{UO}_{2}$ pellets were performed in synthetic COx water representative of the French disposal site groundwater, and in the presence of an iron foil simulating the container. Two types of $\mathrm{UO}_{2}$ pellets were used to reproduce the alpha activity of a UOx spent fuel (burnup $=47$ GWd.t $\mathrm{HM}^{-1}$ ) after 50 or 10000 years of radioactive decay. Samples of solution were taken over time and analyzed ( $\mathrm{U}, \mathrm{Fe}, \mathrm{Eh}, \mathrm{pH}, \mathrm{COx}$ water elements, etc.). At the end of the experiments, surface characterizations by SEM and Raman spectroscopy were performed to detect secondary phase precipitations. Reactive transport modeling was performed with the HYTEC code to help understand the chemical mechanisms involved. The production of $\mathrm{H}_{2} \mathrm{O}_{2}$ by water radiolysis, the $\mathrm{UO}_{2}$ reductive and oxidative dissolutions, the anoxic corrosion of iron and the $\mathrm{Fe}^{2+} / \mathrm{H}_{2} \mathrm{O}_{2}$ reaction were under kinetic control.

In the case of the 10000-years $\mathrm{UO}_{2}$, there was no oxidative dissolution whatever the leaching media involved (carbonated water, COx water, COx water in the presence of iron) and the concentration of uranium (IV) in solution was in equilibrium with $\mathrm{UO}_{2} \bullet \mathrm{xH}_{2} \mathrm{O}(\mathrm{am})$. During the leaching of 50-years $\mathrm{UO}_{2}$ pellets, the concentrations of uranium were close to the solubility limit of $\mathrm{UO}_{2} \bullet \mathrm{xH}_{2} \mathrm{O}(\mathrm{am})$ in the presence of metallic iron. In this case, a Fe(III)-oxihydroxide called akaganeite $(\beta-\mathrm{FeOOH})$ precipitated on the $\mathrm{UO}_{2}$ pellets, and carbonated secondary phases like aragonite $\left(\mathrm{CaCO}_{3}\right)$ and ankerite $\left(\mathrm{CaFe}\left(\mathrm{CO}_{3}\right)_{2}\right)$ were found on the iron foil.

The HYTEC model developed as part of this work led to results in agreement with the experimental observations, and a mechanism for 50 -years $\mathrm{UO}_{2}$ dissolution in groundwater in the presence of metallic iron was then suggested. Fe(II) released in solution by the iron foil anoxic corrosion consumes $\mathrm{H}_{2} \mathrm{O}_{2}$ produced by alpha-radiolysis of water. This redox reaction occurs where radiolytic $\mathrm{H}_{2} \mathrm{O}_{2}$ is produced, i.e. on the surface of the $\mathrm{UO}_{2}$ pellets. The $\mathrm{Fe}(\mathrm{III})$ produced precipitates immediately onto the $\mathrm{UO}_{2}$ pellets as a $\mathrm{Fe}(\mathrm{III})$-oxihydroxide called akaganeite $(\mathrm{FeOOH})$. Thanks to this consumption of $\mathrm{H}_{2} \mathrm{O}_{2}$, the oxidative dissolution of 50 -years $\mathrm{UO}_{2}$ is strongly inhibited by the presence of metallic iron. In parallel, a local increase in $\mathrm{pH}$ around the iron foil due to its anoxic corrosion enables the precipitation of carbonated secondary phases (aragonite, chukanovite, ankerite) onto its surface. Taking into account the experimental results and the reactive transport modeling results, a general mechanism for $\mathrm{UO}_{2}$ dissolution under alpha radiolysis in groundwater in the presence of iron is proposed (Fig. 13). It would seem that the location of the redox front on the surface of $\mathrm{UO}_{2}$ favors the inhibition of oxidizing dissolution under alpha radiolysis which occurs in the very first microns of the reactional interface. The location of this front will, generally speaking, depend on the nature of the irradiation fields, their intensity, and the flux of matter between oxidizing and reducing species coming from the fuel and from the environment. 


\section{[FIGURE 13]}

In the future, it would be interesting to investigate $\mathrm{UO}_{2}$ pellets doped with a chemical element which is insensitive to redox, and dissolved in a fluorite structure, in order to completely validate the inhibition of radionuclide releases at the surface under alpha radiolysis. This remains a major challenge for the modeling of radionuclide behavior in long-term storage situations.

Further leaching experiments are also being run using more complex MIMAS MOx fuel, to study the effects of a heterogeneous microstructure ( $\mathrm{UO}_{2}$ matrix including Pu-enriched agglomerates), and a higher activity due to the presence of these Pu-enriched agglomerates (Odorowski et al., 2016).

\section{Acknowledgements}

This study was carried out under the COSTO research program funded jointly by the CEA, ANDRA and EDF. The authors are grateful to their DHA colleagues and to the personnel of Atalante for their technical support. 


\section{References}

Amme M., Pehrman R., Deutsch R., Roth O. and Jonsson M. (2012) Combined effects of Fe(II) and oxidizing radiolysis products on $\mathrm{UO}_{2}$ and $\mathrm{PuO}_{2}$ dissolution in a system containing solid $\mathrm{UO}_{2}$ and $\mathrm{PuO}_{2}$. J. Nucl. Mater. 430, 1-5.

Boyd V., Yoon H., Zhang C., Oostrom M., Hess N., Fouke B., Valocchi A. J. and Werth C. J. (2014) Influence of $\mathrm{Mg}^{2+}$ on $\mathrm{CaCO}_{3}$ precipitation during subsurface reactive transport in a homogeneous silicon-etched pore network. Geochim. Cosmochim. Acta 135, 321-335.

Broczkowski M. E., Zagidulin D. and Shoesmith D. W. (2010) The Role of Dissolved Hydrogen on the Corrosion/Dissolution of Spent Nuclear Fuel. American Chemical Society Symp. Proc. 1046, 349-380.

Bruno J., Casas I. and Puigdomenech I. (1991) The kinetics of dissolution of $\mathrm{UO}_{2}$ under reducing conditions and the influence of an oxidized surface-layer $\left(\mathrm{UO}_{2+\mathrm{x}}\right)$ - Application of a continuous flowthrough reactor. Geochim. Cosmochim. Acta 55, 647-658.

Bruno J. and Spahiu K. (2014) The long-term effect of hydrogen on the $\mathrm{UO}_{2}$ spent fuel stability under anoxic conditions: Findings from the Cigar Lake Natural Analogue study. Appl. Geochem. 49, 178-183.

Carbol P., Fors P., Gouder T. and Spahiu K. (2009) Hydrogen suppresses $\mathrm{UO}_{2}$ corrosion. Geochim. Cosmochim. Acta 73, 4366-4375.

Crane R. A., Dickinson M. and Scott T. B. (2015) Nanoscale zero-valent iron particles for the remediation of plutonium and uranium contaminated solutions. Chem. Eng. J. 262, 319-325.

Cui D. Q. and Spahiu K. (2002) The reduction of $U(\mathrm{VI})$ on corroded iron under anoxic conditions. Radiochim. Acta 90, 623-628.

Cui D. Q., Low J. and Spahiu K. (2011) Environmental behaviors of spent nuclear fuel and canister materials. Energy Environ. Sci. 4, 2537-2545.

De Choudens-Sanchez V. and Gonzalez L. A. (2009) Calcite and aragonite precipitation under controlled instantaneous supersaturation: Elucidating the role of $\mathrm{CaCO}_{3}$ saturation state and $\mathrm{Mg} / \mathrm{Ca}$ ratio on calcium carbonate polymorphism. J. Sed. Res. 79, 363-376.

De Combarieu G., Barboux P. and Minet Y. (2007) Iron corrosion in Callovian-Oxfordian argilite: From experiments to thermodynamic/kinetic modelling. Phys. Chem. Earth 32, 346-358.

De Faria D. L. A. and Lopes F. N. (2007) Heated goethite and natural hematite: Can Raman spectroscopy be used to differentiate them? Vib. Spectrosc. 45, 117-121.

Du X., Boonchayaanant B., Wu W. M., Fendorf S., Bargar J. and Criddle C. S. (2011) Reduction of uranium(VI) by soluble iron(II) conforms with thermodynamic predictions. Environ. Sci. Technol. 45, 4718-4725.

Ekeroth E., Roth O. and Jonsson M. (2006) The relative impact of radiolysis products in radiation induced oxidative dissolution of $\mathrm{UO}_{2}$. J. Nucl. Mater. 355, 38-46.

Eliet V. and Bidoglio G. (1998) Kinetics of the laser-induced photoreduction of U(VI) in aqueous suspensions of $\mathrm{TiO}_{2}$ particles. Environ. Sci. Technol. 32, 3155-3161.

Ewing R. C. (2015) Long-term storage of spent nuclear fuel. Nat. Mater. 14, 252-257.

Fanghänel T., Rondinella V. V., Glatz J. P., Wiss T., Wegen D. H., Gouder T., Carbol P., Serrano-Purroy D. and Papaioannou D. (2013) Reducing Uncertainties Affecting the Assessment of the Long-Term Corrosion Behavior of Spent Nuclear Fuel. Inorg. Chem 52, 3491-3509. 
Gaucher E. C., Blanc P., Bardot F., Braibant G., Buschaert S., Crouzet C., Gautier A., Girard J-P., Jacquot E., Lassin A., Negrel G., Tournassat C., Vinsot A. and Altmann S. (2006) Modelling the porewater chemistry of the Callovian-Oxfordian formation at a regional scale. C. R. Geosci. 338, 917930.

Giffaut E., Grive M., Blanc P., Vieillard P., Colas E., Gailhanou H., Gaboreau S., Marty N., Made B. and Duro L. (2014) Andra thermodynamic database for performance assessment: ThermoChimie. Appl. Geochem. 49, 225-236.

Grambow B, Smailos E., Geckeis H., Muller R. and Hentschel H. (1996) Sorption and reduction of uranium( $\mathrm{VI}$ ) on iron corrosion products under reducing saline conditions. Radiochim. Acta 74, 149154.

Gu B., Liang L., Dickey M. J., Yin X. and Dai S. (1998) Reductive precipitation of uranium(VI) by zerovalent iron. Environ. Sci. Technol. 32, 3366-3373.

Guillaumont R., Fanghanel T., Neck V., Fuger J., Palmer D. A., Grenthe I. and Rand M. H. (2003) Update on the Chemical Thermodynamics of Uranium, Neptunium, Plutonium, Americium, and Technetium. Elsevier, Amsterdam, The Netherlands.

Latta D. E., Mishra B., Cook R. E., Kemner K. M. and Boyanov M. I. (2014) Stable U(IV) complexes form at high-affinity mineral surface sites. Environ. Sci. Technol. 48, 1683-1691.

Lee S., Sin D. H. and Cho K. (2015) $\mathrm{CaCO}_{3}$ Precipitation and Polymorph Forms During $\mathrm{CO}_{2}$ Sequestration from the Atmosphere: Effects of the Basic Buffer Components. Cryst. Growth Des. 15, 610-616.

Liger E., Charlet L. and Van Cappellen P. (1999) Surface catalysis of uranium(VI) reduction by iron(II). Geochim. Cosmochim. Acta 63, 2939-2955.

Liu N., Wu L., Qin Z. and Shoesmith, D. W. (2016) Roles of Radiolytic and Externally Generated $\mathrm{H}_{2}$ in the Corrosion of Fractured Spent Nuclear Fuel. Environ. Sci. Technol. 50, 12348-12355.

Loida A., Grambow B. and Geckeis H. (1996) Anoxic corrosion of various high burnup spent fuel samples. J. Nucl. Mater. 238, 11-22.

Lousada C. M., Trummer M. and Jonsson M. (2013) Reactivity of $\mathrm{H}_{2} \mathrm{O}_{2}$ towards different $\mathrm{UO}_{2}$-based materials: The relative impact of radiolysis products revisited. J. Nucl. Mater. 434, 434-439.

Mavromatis V., Montouillout V., Noireaux J., Gaillardet J. and Schott J. (2015) Characterization of boron incorporation and speciation in calcite and aragonite from co-precipitation experiments under controlled pH, temperature and precipitation rate. Geochim. Cosmochim. Acta 150, 299-313.

Merino J., Cera E., Bruno J., Quinones J., Casas I., Clarens F., Gimenez J., de Pablo J., Rovira M. and Martinez-Esparza A. (2005) Radiolytic modelling of spent fuel oxidative dissolution mechanism. Calibration against $\mathrm{UO}_{2}$ dynamic leaching experiments. J. Nucl. Mater. 346, 40-47.

Muzeau B., Jegou C., Delaunay F., Broudic V., Brevet A., Catalette H., Simoni E. and Corbel C. (2009) Radiolytic oxidation of $\mathrm{UO}_{2}$ pellets doped with alpha-emitters (Pu-238/239). J. Alloys Compd. 467, 578-589.

Neck V. and Kim J. I. (2001) Solubility and hydrolysis of tetravalent actinides. Radiochim. Acta 89, 116.

Neff D. (2003) Apport des analogues archéologiques à l'estimation des vitesses moyennes et à l'étude des mécanismes de corrosion à très long terme des aciers non alliés dans les sols. Ph. D. thesis, Université de Technologie de Compiègne, France. 
Niedermayr A., Koehler S. J. and Dietzel M. (2013) Impacts of aqueous carbonate accumulation rate, magnesium and polyaspartic acid on calcium carbonate formation (6-40 degrees C). Chem. Geol. 340, 105-120.

Odegaard-Jensen A. and Oversby V. (2008) Testing of uranium dioxide containing different levels of alpha activity under anaerobic and reducing conditions. Mat. Res. Soc. Symp. Proc. 1104, 115-120.

Odorowski M., Jégou C., De Windt L., Broudic V., Peuget S., Magnin M., Tribet M. and Martin C. (2016) Oxidative dissolution of unirradiated Mimas MOX fuel (U/Pu oxides) in carbonated water under oxic and anoxic conditions. J. Nucl. Mater. 468, 17-25.

O'Loughlin E. J., Kelly S. D., Cook R. E., Csencsits R. and Kemner K. M. (2003) Reduction of uranium(VI) by mixed iron(II)/iron(III) hydroxide (green rust): Formation of $\mathrm{UO}_{2}$ nanoparticles. Environ. Sci. Technol. 37, 721-727.

Pandarinathan V., Lepkova K. and van Bronswijk W. (2014) Chukanovite $\left(\mathrm{Fe}_{2}(\mathrm{OH})_{2} \mathrm{CO}_{3}\right)$ identified as a corrosion product at sand-deposited carbon steel in $\mathrm{CO}_{2}$-saturated brine. Corros. Sci. 85, 26-32.

Poinssot C., Ferry C., Kelm M., Grambow B., Martinez A., Johnson L., Andriambololona Z., Bruno J., Cachoir C., Cavedon J. M., Christensen H., Corbel C., Jegou C., Lemmens K., Loida A., Lovera P., Miserque F., De Pablo J., Poulesquen A., Quinones J., Spahiu K. and Wegen D. (2005) Spent fuel stability under repository conditions - Final report of the European project. 5th Euratom framework program 1998-2002. France CEA, Contract $n^{\circ}$ FIKW-CT-2001-00192 SFS.

Remazeilles C. and Refait P. (2007) On the formation of beta-FeOOH (akaganeite) in chloridecontaining environments. Corros. Sci. 49, 844-857.

Romaine A., Sabot R., Jeannin M., Necib S. and Refait P. (2013) Electrochemical synthesis and characterization of corrosion products on carbon steel under argillite layers in carbonated media at 80 degrees C. Electrochim. Acta 114, 152-158.

Rondinella V. V., Cobos J. and Wiss T. (2004) Leaching behaviour of low-activity alpha-doped $\mathrm{UO}_{2}$. Mat. Res. Soc. Symp. Proc. 824, 167-173.

RRUFF online database. www.rruff.info

Saheb M., Neff D., Dillmann P., Matthiesen H. and Foy E. (2008) Long-term corrosion behaviour of low-carbon steel in anoxic environment: Characterisation of archaeological artefacts. J. Nucl. Mater. 379, 118-123.

Schlegel M. L., Bataillon C., Brucker F., Blanc C., Pret D., Foy E. and Chorro M. (2014) Corrosion of metal iron in contact with anoxic clay at 90 degrees $C$ : Characterization of the corrosion products after two years of interaction. Appl. Geochem. 51, 1-14.

Shoesmith D. W. (2000) Fuel corrosion processes under waste disposal conditions. J. Nucl. Mater. 282, 1-31.

Sousa M. H., Rubim J. C., Sobrinho P. G. and Tourinho F. A. (2001) Biocompatible magnetic fluid precursors based on aspartic and glutamic acid modified maghemite nanostructures. J. Magn. Magn. Mater. 225, 67-72.

Spahiu K., Werme L., Low J. and Eklund U. B. (2000) In situ long term measurements of pH and redox potential during spent fuel leaching under stationary conditions - The method and some preliminary results. Mat. Res. Soc. Symp. Proc. 608, 55-60.

Spahiu K., Cui D. Q. and Lundstrom M. (2004a) The fate of radiolytic oxidants during spent fuel leaching in the presence of dissolved near field hydrogen. Radiochim. Acta 92, 625-629.

Spahiu K., Devoy J., Cui D. and Lundström M. (2004b) The reduction of U(VI) by near field hydrogen in the presence of $\mathrm{UO}_{2}(\mathrm{~s})$. Radiochim. Acta 92, 597-601. 
Sunagawa I., Takahashi Y. and Imai H. (2007) Strontium and aragonite-calcite precipitation. J. Miner. Petrol. Sci. 102, 174-181.

Tournassat C., Blanc P. and Gaucher E. (2008) Estimation de la composition de l'eau porale du Callovo-Oxfordien à $50,70,80$ et $90^{\circ} \mathrm{C}$. Report BRGM/RP-56171-FR.

Tribet M., Jegou C., Broudic V., Marques C., Rigaux P. and Gavazzi, A. (2010) Leaching of $\mathrm{UO}_{2}$ pellets doped with alpha- emitters ((238/239)Pu) in synthetic deep Callovian-Oxfordian groundwater. Mater. Sci. Eng. 9, 012009.

Trummer M. and Jonsson M. (2010) Resolving the $\mathrm{H}_{2}$ effect on radiation induced dissolution of $\mathrm{UO}_{2^{-}}$ based spent nuclear fuel. J. Nucl. Mater. 396, 163-169.

Ulrich K. U., Singh A., Schofield E. J., Bargar J. R., Veeramani H., Sharp J. O., Bernier-Latmani R. and Giammar D. E. (2008) Dissolution of biogenic and synthetic $\mathrm{UO}_{2}$ under varied reducing conditions. Environ. Sci. Technol. 42, 5600-5606.

van der Lee J., De Windt L., Lagneau V. and Goblet P. (2003) Module-oriented modeling of reactive transport with HYTEC. Comput. Geosci. 29, 265-275.

Wersin P., Johnson L.H., Schwyn B., Berner U., Curti, E. (2003) Redox conditions in the near field of a repository for SF/HLW and ILW in Opalinus Clay. Technical report 02-13, Nagra, Wettingen (Switzerland).

Zhu Z., Tao L. and Li F. (2013) Effects of dissolved organic matter on adsorbed Fe(II) reactivity for the reduction of 2-nitrophenol in $\mathrm{TiO}_{2}$ suspensions. Chemosphere 93, 29-34. 


\section{Figure captions}

Fig. 1. Evolution of uranium concentrations in solution during leaching of 50-years $\mathrm{UO}_{2}$ pellets in different environments. The results of Ref $\mathrm{UO}_{2}$ leaching in synthetic $\mathrm{COx}$ water are also indicated. The solubility limit of $\mathrm{UO}_{2} \bullet 2 \mathrm{H}_{2} \mathrm{O}(\mathrm{am})$ are calculated for two different thermodynamic constants (LogK). The grey area corresponds to the lower uncertainty range of solubility values given by Neck and Kim (Neck and Kim, 2001). F: filtered sample. UF: ultra-filtered sample.

Fig. 2. Evolution of uranium concentrations in solution during leaching of 10000 -years $\mathrm{UO}_{2}$ pellets in different environments. The results of Ref $\mathrm{UO}_{2}$ leaching in synthetic COx water are also indicated. The solubility limit of $\mathrm{UO}_{2} \bullet 2 \mathrm{H}_{2} \mathrm{O}(\mathrm{am})$ are calculated for two different thermodynamic constants (LogK). The grey area corresponds to the lower uncertainty range of solubility values given by Neck and Kim (Neck and Kim, 2001). F: filtered sample. UF: ultra-filtered sample.

Fig. 3. Distribution of uranium between the solution, the colloids, and the sorbed/precipitated fraction on the iron foil or on the $\mathrm{TiO}_{2}$ reactor at the end of the leaching experiments in synthetic $\mathrm{COx}$ water in the presence of metallic iron: a) for 50 -years $\mathrm{UO}_{2}$ pellets, b) for 10000 -years $\mathrm{UO}_{2}$ pellets.

Fig. 4. Evolution of iron concentrations in solution during leaching of different $\cup_{2}$ pellets in synthetic COx water in the presence of an iron foil. F: filtered sample. UF: ultra-filtered sample.

Fig. 5. SEM micrographs of different $\mathrm{UO}_{2}$ pellets after leaching in synthetic $\mathrm{COx}$ water in the presence of metallic iron: $\mathrm{a}-\mathrm{b}) \mathrm{50}$-years $\mathrm{UO}_{2}$ pellet, and c-d) 10000 -years $\mathrm{UO}_{2}$ pellet.

Fig. 6. EDX analyses of precipitates found on the 50-years $\mathrm{UO}_{2}$ pellets and the 10000-years $\mathrm{UO}_{2}$ pellets leached in synthetic COx water in the presence of metallic iron.

Fig. 7. Raman spectrum of precipitates found on the 50 -years $\mathrm{UO}_{2}$ and the 10000 -years $\mathrm{UO}_{2}$ pellets leached in synthetic COx water in the presence of metallic iron and comparison with literature data (acquisition power $=\sim 0.6 \mathrm{~mW}$ ).

Fig. 8. SEM micrographs of iron foils corroded in synthetic COx water in the presence of a-c) 50-years $\mathrm{UO}_{2}$ pellets, and d-f) 10000 -years $\mathrm{UO}_{2}$ pellets.

Fig. 9. Raman spectrum of precipitates found on the iron foils corroded in synthetic COx water in the presence of different $\mathrm{UO}_{2}$ pellets: a) Sr-aragonite (from 50-years $\mathrm{UO}_{2}$ experiment), b) Sr-aragonite (from 10000-years $\mathrm{UO}_{2}$ experiment), c) ankerite, d) chukanovite.

Fig. 10. Modeling results of the alteration of 50 -years $\mathrm{UO}_{2}$ pellets in synthetic $\mathrm{COx}$ water in the presence of an iron foil. Without any pre-corrosion step of iron, the production of a $\mathrm{H}_{2} \mathrm{O}_{2}$ plume (a) by water radiolysis leads to the release of uranium in solution by the $\mathrm{UO}_{2}$ pellets (b), whereas the production of a Fe(II) plume in solution by corrosion (c) progressively depletes $\mathrm{H}_{2} \mathrm{O}_{2}$ in solution. When a pre-corrosion step is considered, $\mathrm{Fe}(\mathrm{II})$ (f) directly inhibits the production of $\mathrm{H}_{2} \mathrm{O}_{2}$ (d) and the oxidative dissolution of $\mathrm{UO}_{2}(\mathrm{e})$.

Fig. 11. Modeling results of alteration of 50 -years $\mathrm{UO}_{2}$ pellets in synthetic $\mathrm{COx}$ water in the presence of an iron foil after 450 days: a) simulation grid, b) precipitation of goethite ( $\mathrm{FeOOH}$ ) and c) precipitation of $\mathrm{UO}_{2} \bullet 2 \mathrm{H}_{2} \mathrm{O}(\mathrm{am})$ on the $\mathrm{UO}_{2}$ pellets; d) a ten fold increase of the intensity of the alpha radiolysis displaces the $\mathrm{FeOOH}$ precipitation front.

Fig. 12. Modeling results of alteration of 50 -years $\mathrm{UO}_{2}$ pellets in synthetic $\mathrm{COx}$ water in the presence of an iron foil after 450 days: a) preferential precipitation of calcite $\left(\mathrm{CaCO}_{3}\right)$ and b) siderite $\left(\mathrm{FeCO}_{3}\right)$ on the iron foil due to a slight increase of $\mathrm{pH}$ (c) resulting from the metallic iron corrosion.

Fig. 13. Mechanism of 50-years $\mathrm{UO}_{2}$ alteration in synthetic $\mathrm{COx}$ water in the presence of metallic iron (foil). 


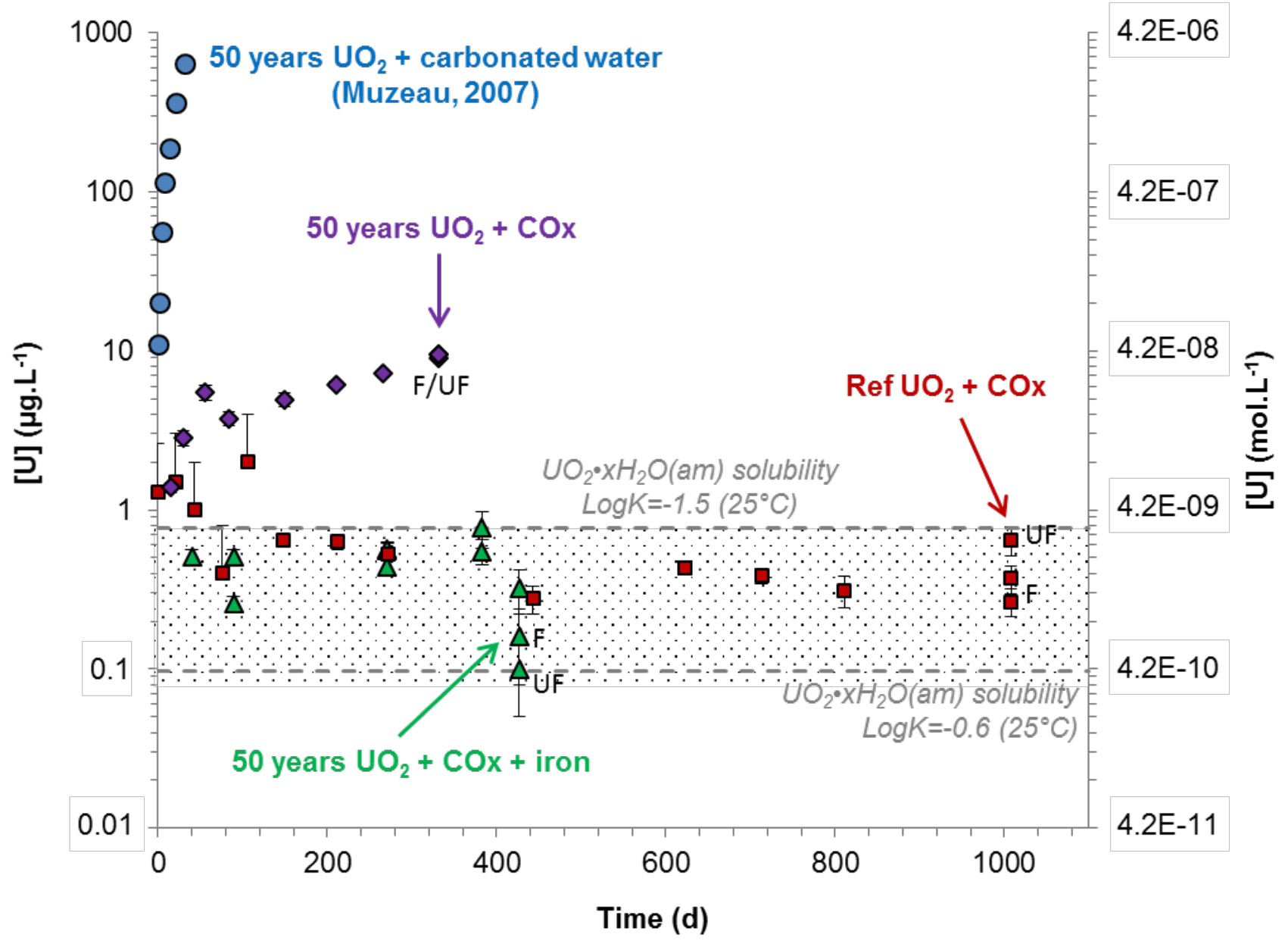

FIGURE 1 


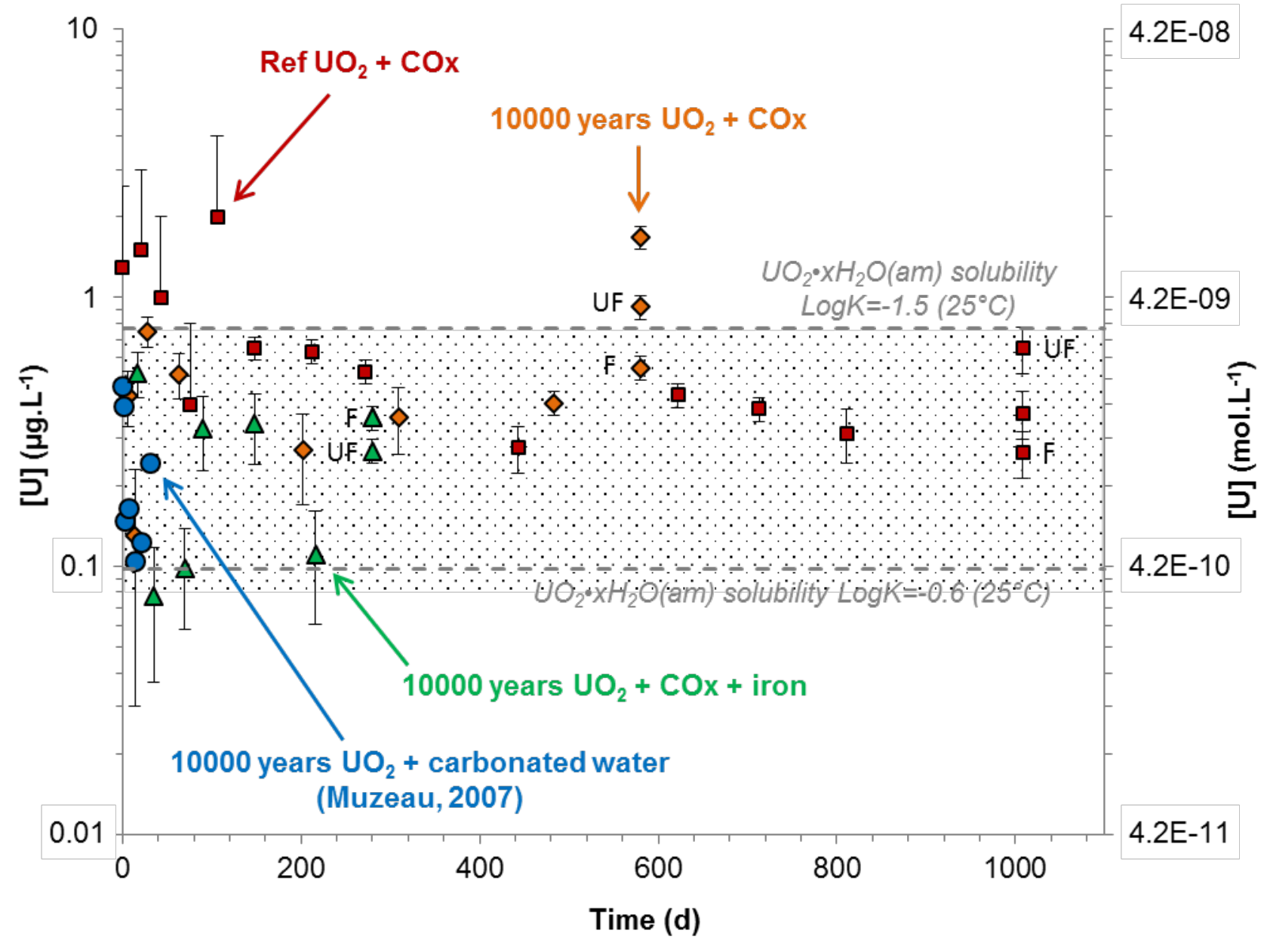

FIGURE 2 

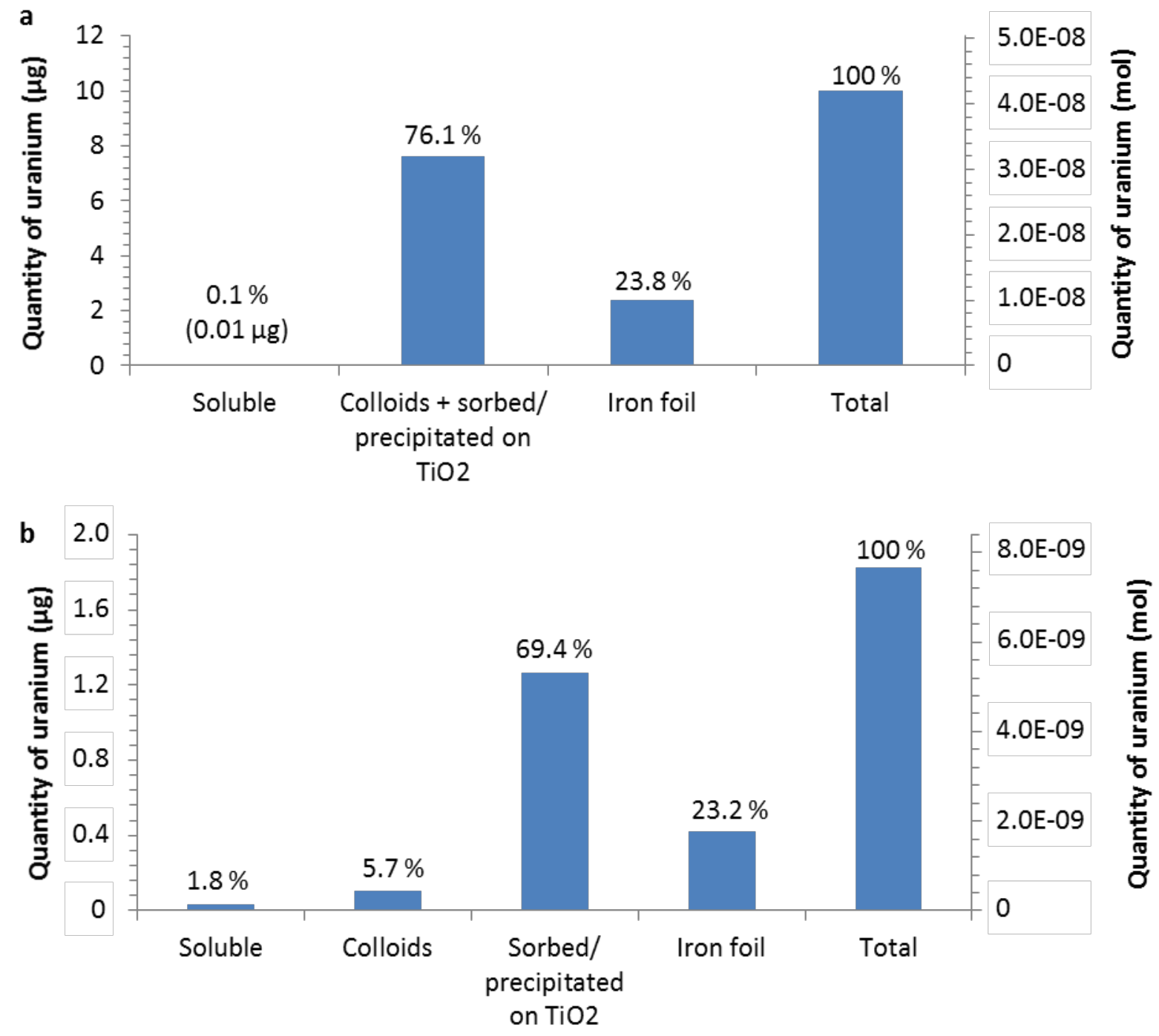

FIGURE 3 


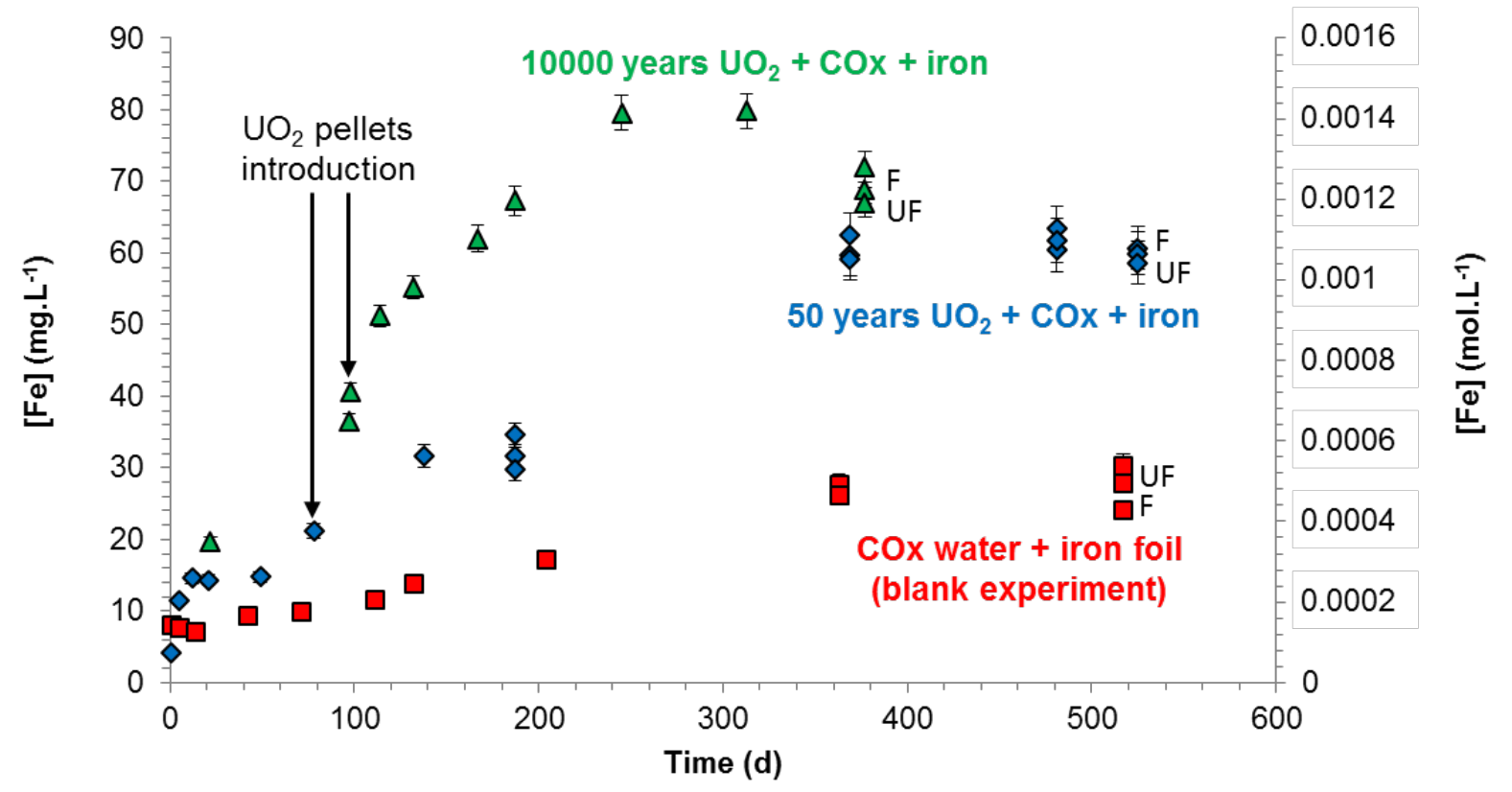

FIGURE 4 
50 years $\mathrm{UO}_{2}$

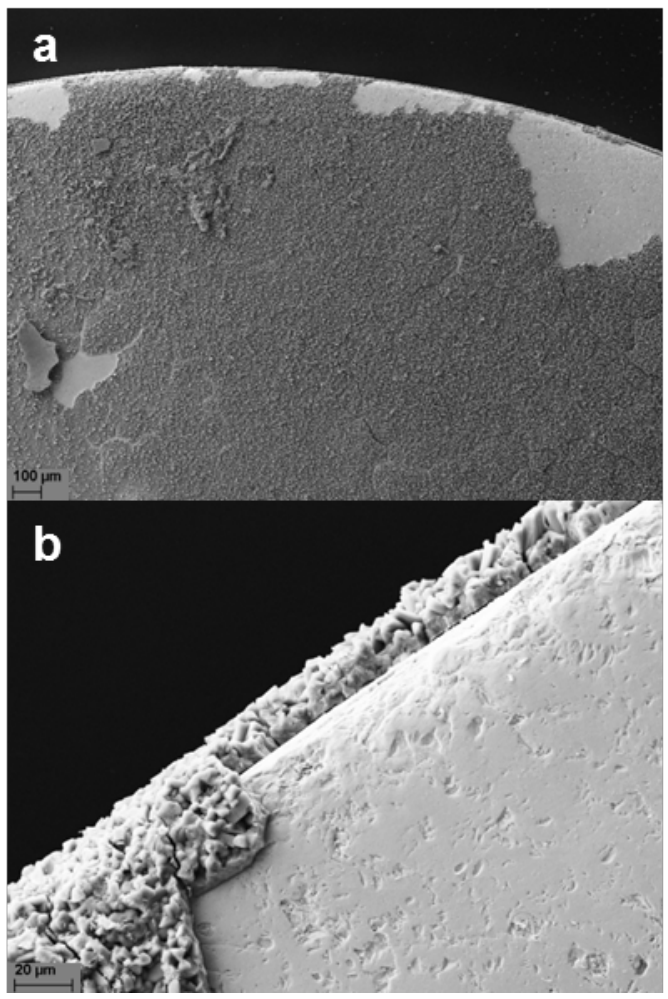

10000 years $\mathrm{UO}_{2}$

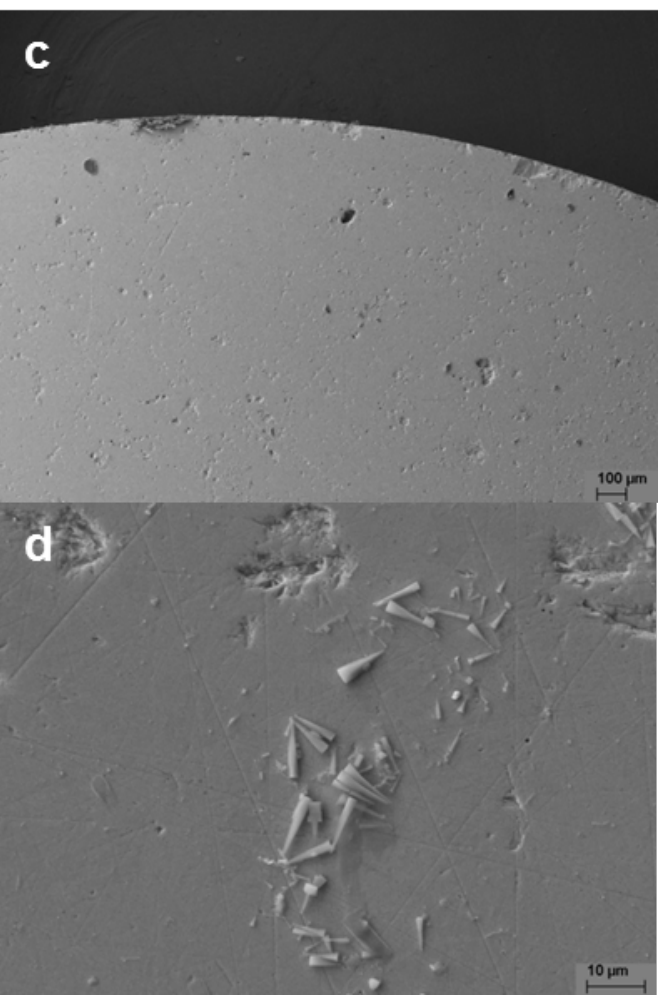

FIGURE 5 


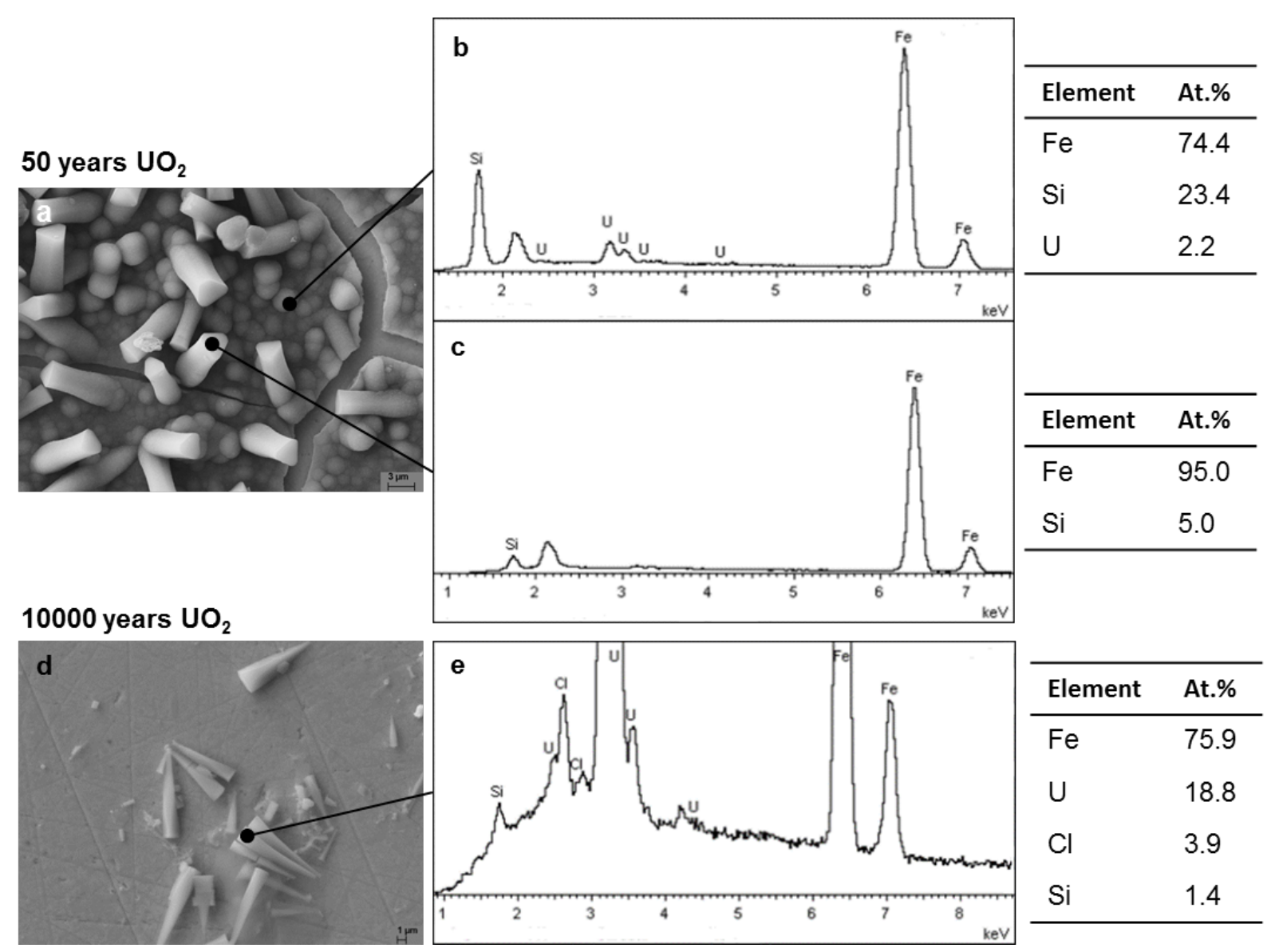

FIGURE 6 


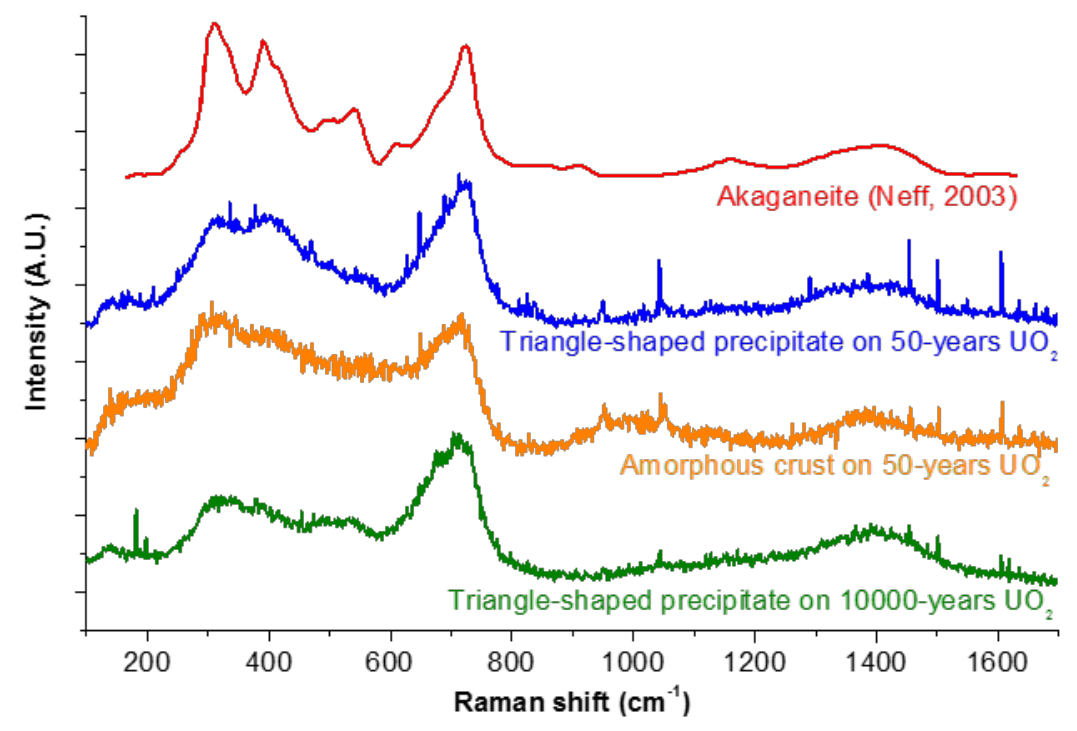

FIGURE 7 


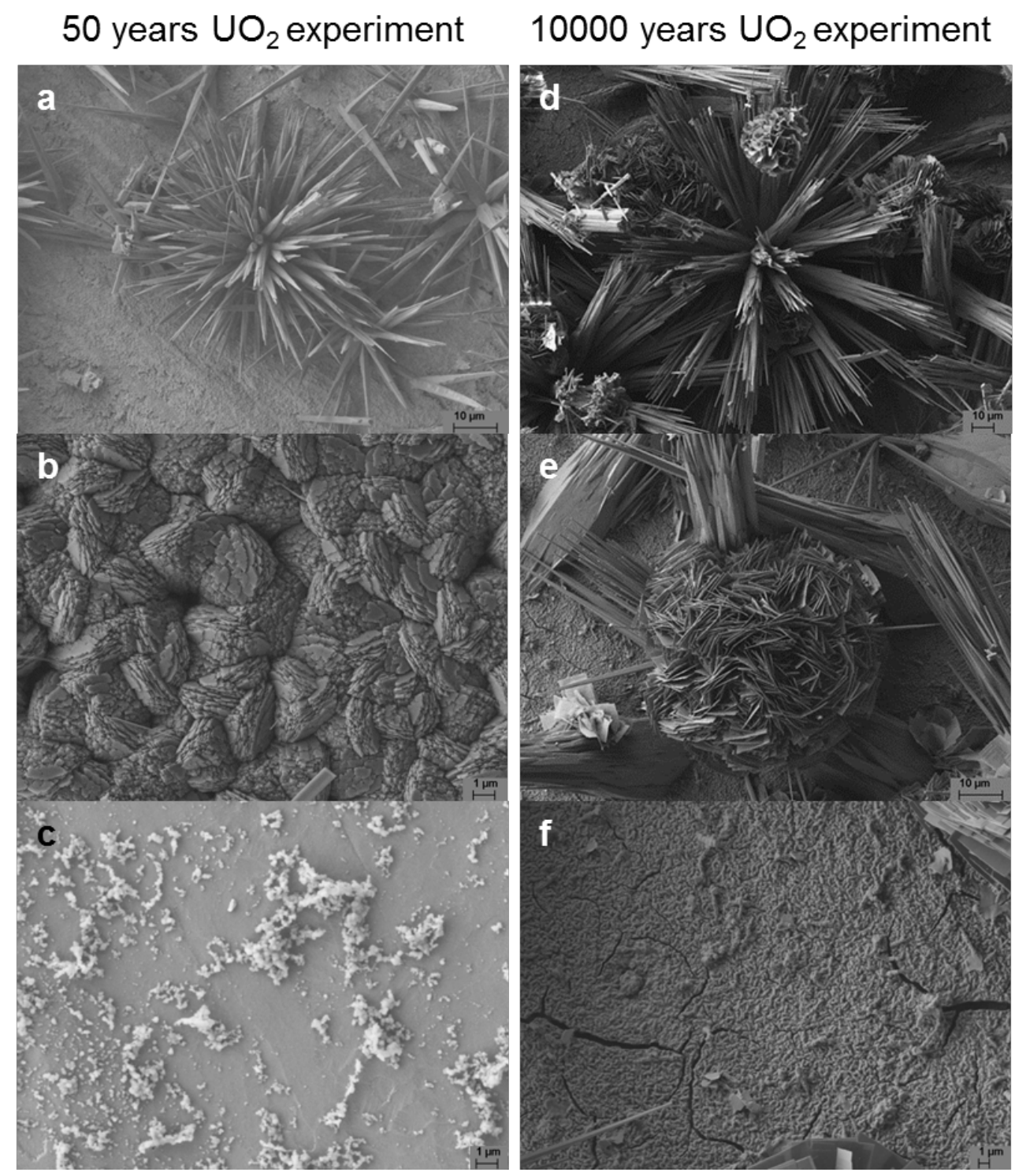

FIGURE 8 


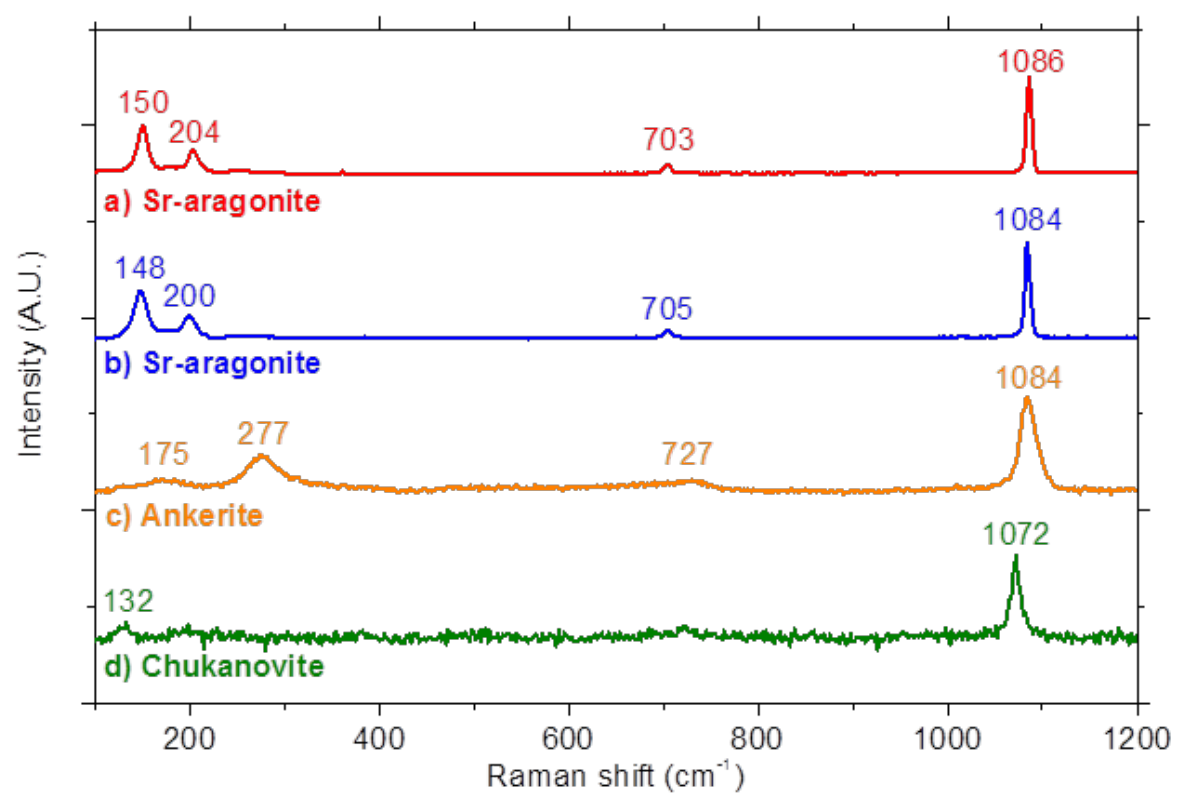

FIGURE 9 
(a) Dissolved $\mathrm{H}_{2} \mathrm{O}_{2}$ at 5 \& 30 hours without pre-corrosion
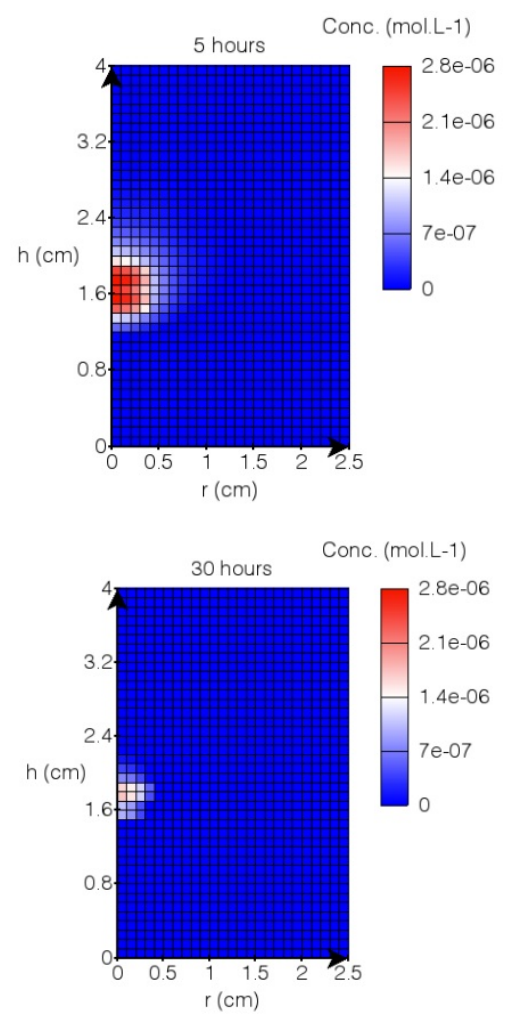

(d) Dissolved $\mathrm{H}_{2} \mathrm{O}_{2} 5$ hours with pre-corrosion

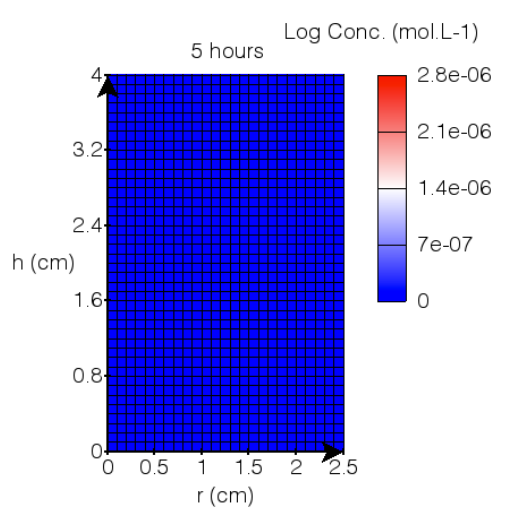

(b) Dissolved U at 5 \& 30 hours without pre-corrosion

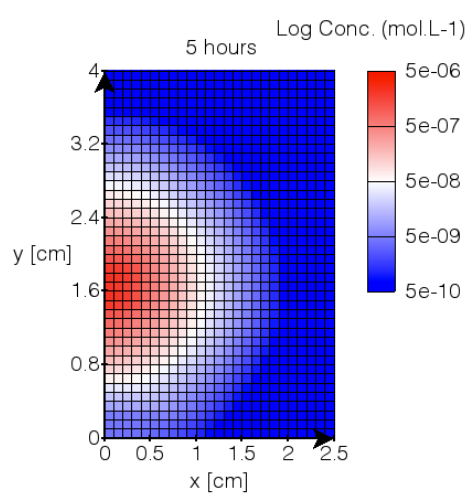

Log Conc. (mol.L-1)

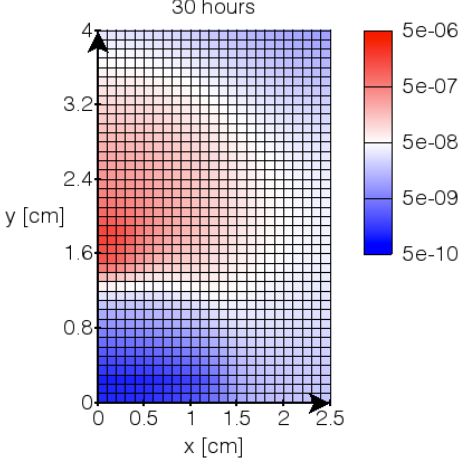

(e) Dissolved U at 5 hours with pre-corrosion

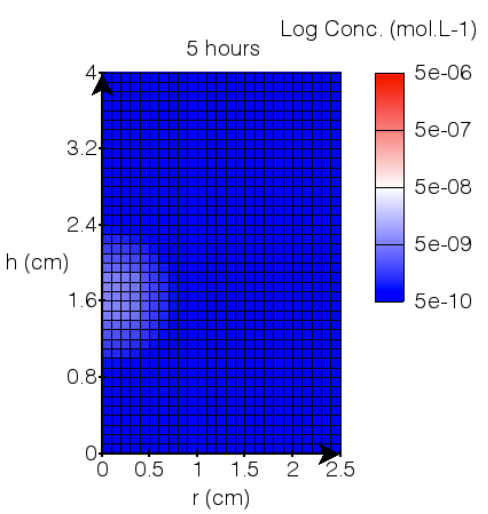

(c) Dissolved Fe at $5 \& 30$ hours without pre-corrosion
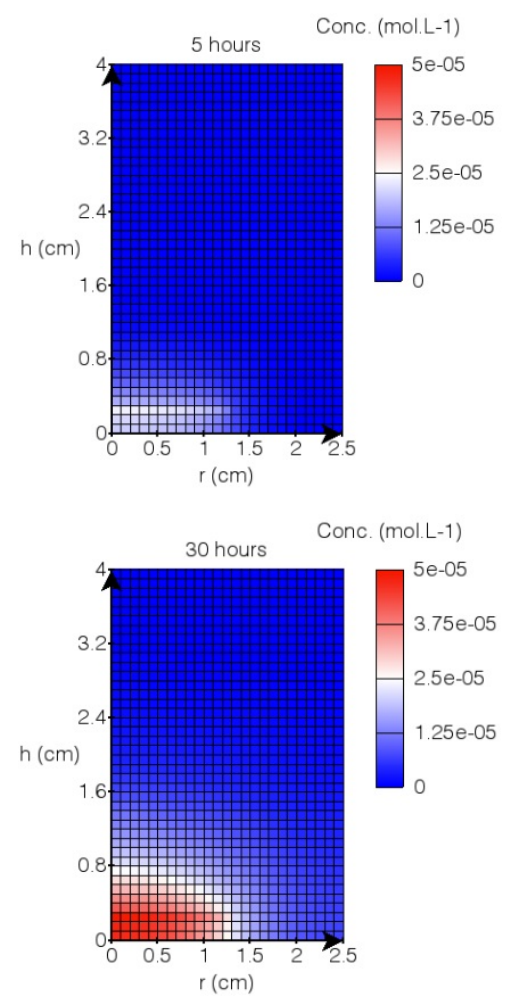

(f) Dissolved Fe at 5 hours with pre-corrosion

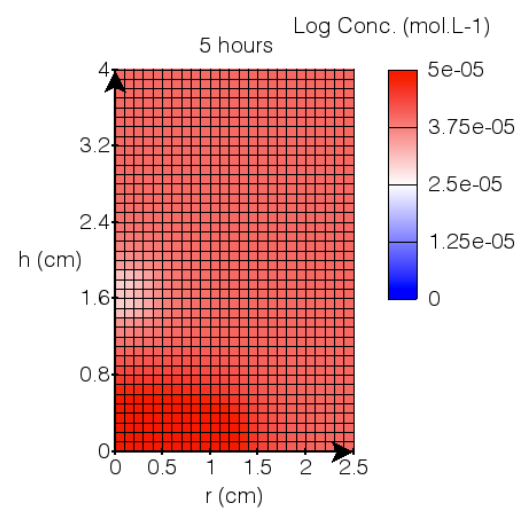

FIGURE 10 
(a) Simulation grid

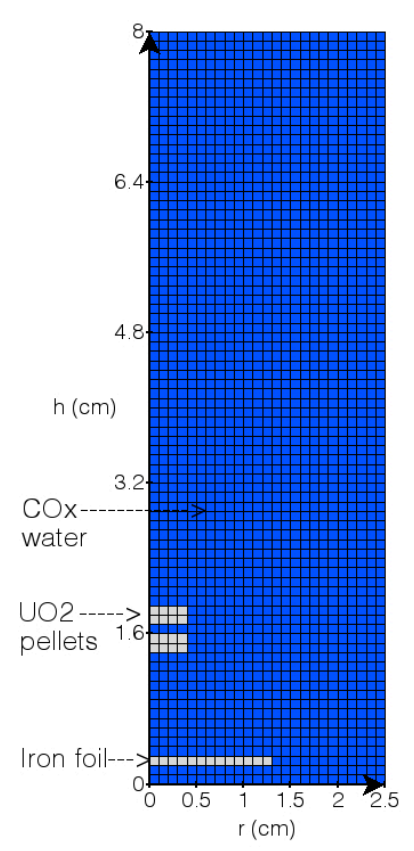

(b) $\mathrm{FeOOH}$

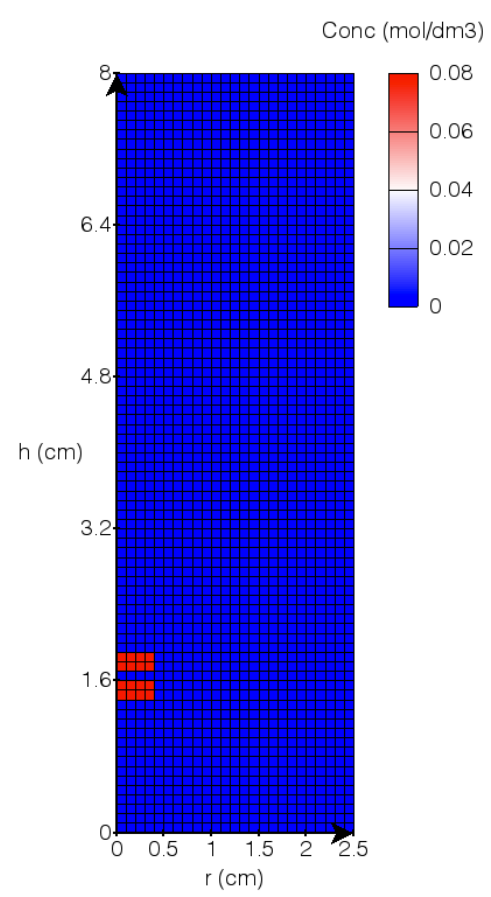

(c) $\mathrm{UO}_{2} \cdot 2 \mathrm{H}_{2} \mathrm{O}(\mathrm{am})$

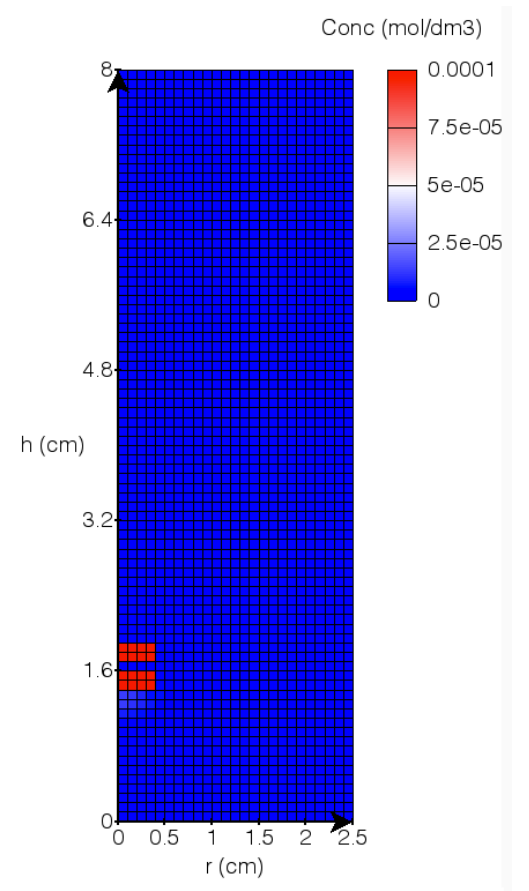

(d) FeOOH - radiolysis $\times 10$

Conc (mol/dm3)

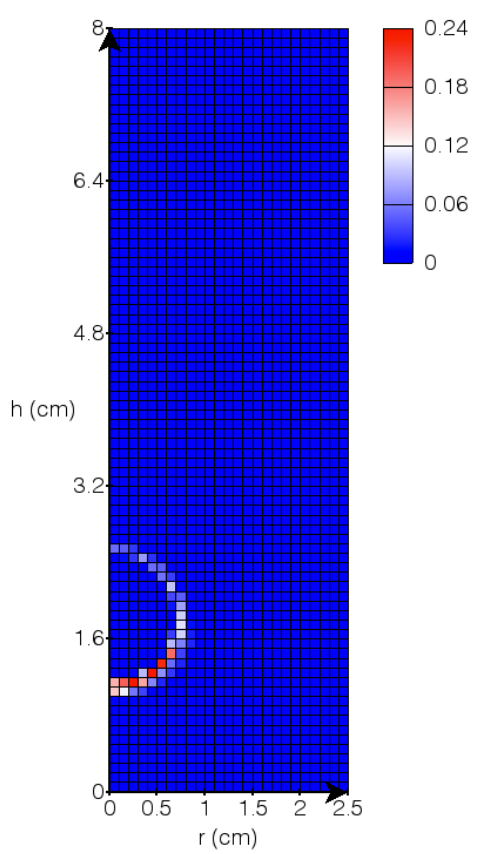

FIGURE 11 
(a) $\mathrm{CaCO}_{3}$

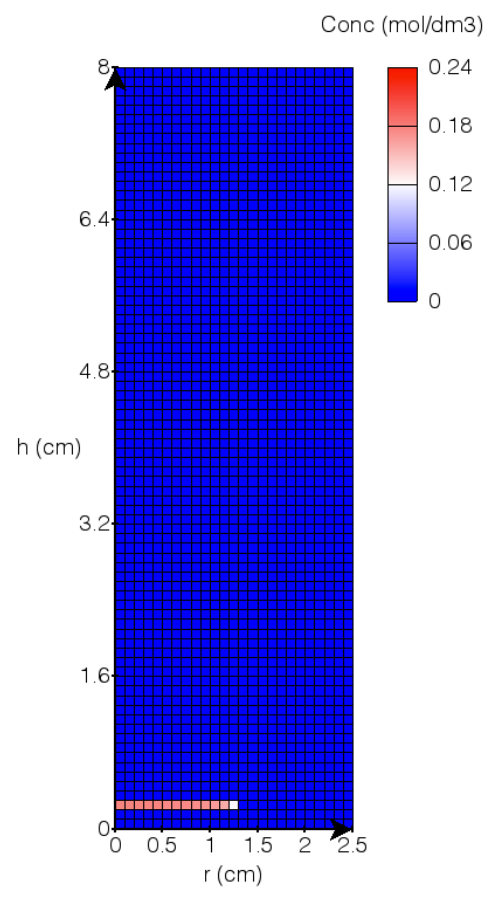

(b) $\mathrm{FeCO}_{3}$

Conc (mol/dm3)

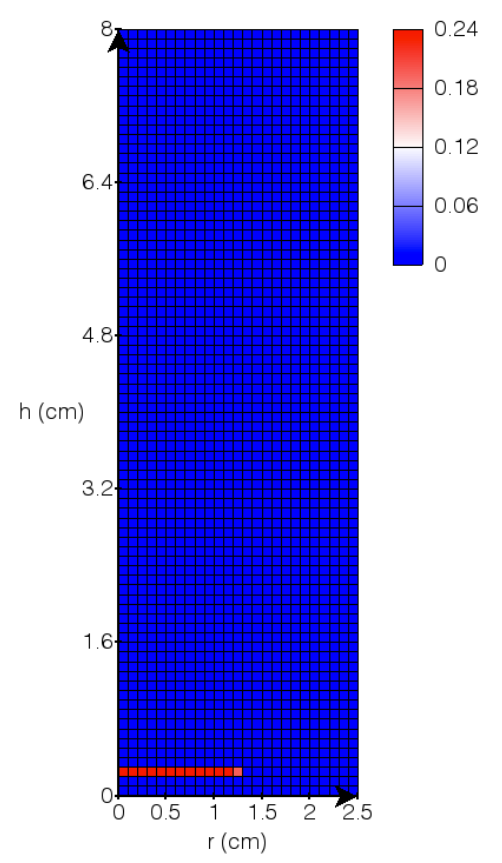

(c) $\mathrm{pH}$

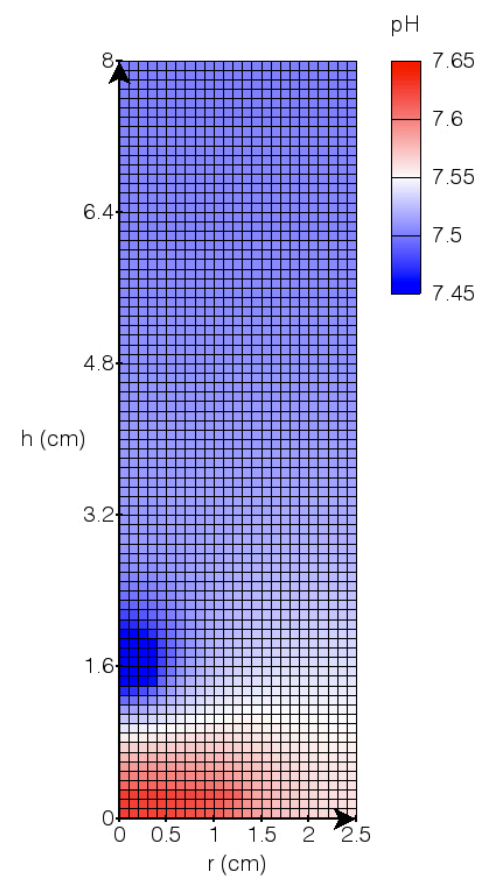

FIGURE 12 


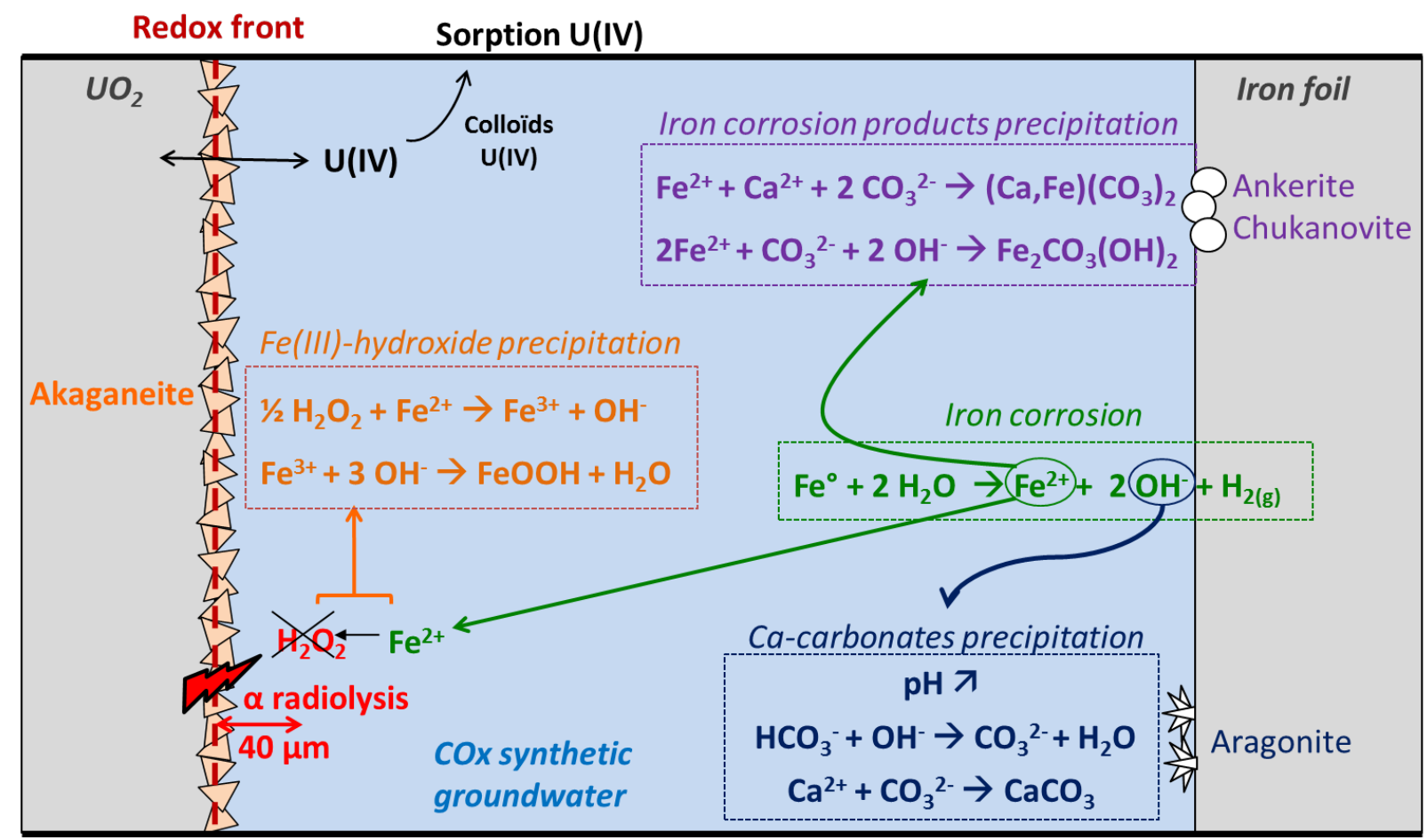

FIGURE 13 


\section{Tables}

Table 1

Composition and alpha activity of the different Pu-doped $\mathrm{UO}_{2}$ pellets used in the experiments.

\begin{tabular}{|c|c|c|c|c|c|c|c|c|c|}
\hline \multirow{2}{*}{$\begin{array}{l}\text { Type } \\
\text { of } \mathrm{UO}_{2}\end{array}$} & \multirow{2}{*}{$\begin{array}{l}\text { Alpha } \\
\text { activity } \\
\text { (MBq.g }^{-1}{ }^{-1} \text { ) }\end{array}$} & \multicolumn{8}{|c|}{ Composition (wt\%) } \\
\hline & & $\mathrm{U}_{\text {tot }}$ & ${ }^{235} \mathrm{U}$ & $\mathrm{Pu}_{\text {tot }}$ & ${ }^{238} \mathrm{Pu}$ & ${ }^{239} \mathrm{Pu}$ & ${ }^{240} \mathrm{Pu}$ & ${ }^{241} \mathrm{Pu}$ & ${ }^{242} \mathrm{Pu}$ \\
\hline Reference & 0.01 & 88.15 & 0.185 & - & - & - & - & - & - \\
\hline 50-years & 385 & 87.83 & 0.184 & 0.218 & 0.060 & 0.107 & 0.044 & 0.002 & 0.005 \\
\hline 10000-years & 18 & 87.83 & 0.184 & 0.218 & 0.001 & 0.143 & 0.064 & 0.003 & 0.007 \\
\hline
\end{tabular}

Table 2

Characteristics of all the leaching tests realized.

\begin{tabular}{lllll}
\hline Type of $\mathrm{UO}_{2}$ & Solution & Atmosphere & Other object & Time of leaching \\
\hline Reference & synthetic $\mathrm{CO}$ water & $\mathrm{Ar} / \mathrm{CO}_{2} 3000 \mathrm{ppm}$ & - & 1008 days \\
50 -years & synthetic $\mathrm{CO}$ water & $\mathrm{Ar} / \mathrm{CO}_{2} 3000 \mathrm{ppm}$ & - & 331 days \\
50 -years & synthetic $\mathrm{CO}$ water & $\mathrm{Ar} / \mathrm{CO}_{2} 3000 \mathrm{ppm}$ & Iron foil & 525 days \\
10000 -years & synthetic $\mathrm{CO}$ water & $\mathrm{Ar} / \mathrm{CO}_{2} 3000 \mathrm{ppm}$ & - & 580 days \\
10000 -years & synthetic COx water & $\mathrm{Ar} / \mathrm{CO}_{2} 3000 \mathrm{ppm}$ & Iron foil & 377 days \\
& synthetic COx water & $\mathrm{Ar} / \mathrm{CO}_{2} 3000 \mathrm{ppm}$ & Iron foil & 517 days \\
\hline
\end{tabular}

Table 3

Expected composition of the synthetic Callovian-Oxfordian groundwater at $25^{\circ} \mathrm{C}$.

\begin{tabular}{lccccccccc}
\hline & {$\left[\mathrm{Na}^{+}\right]$} & {$\left[\mathrm{K}^{+}\right]$} & {$\left[\mathrm{Ca}^{2+}\right]$} & {$\left[\mathrm{Mg}^{2+}\right]$} & {$\left[\mathrm{Sr}^{2+}\right]$} & {$\left[\mathrm{Cl}^{-}\right]$} & {$\left[\mathrm{SO}_{4}{ }^{2-}\right]$} & {$\left[\mathrm{HCO}_{3}{ }^{-}\right]$} & {$[\mathrm{Si}]$} \\
\hline $\mathrm{mg} \cdot \mathrm{L}^{-1}$ & 993 & 39.1 & 341 & 131 & 17.5 & 1454 & 1412 & 146 & 5.62 \\
$\mathrm{~mol} . \mathrm{L}^{-1}$ & 0.0432 & 0.0010 & 0.0085 & 0.0054 & 0.0002 & 0.0410 & 0.0147 & 0.0024 & 0.0002 \\
\hline
\end{tabular}




\section{Table 4}

Reactions of formation and associated thermodynamic constants at $25^{\circ} \mathrm{C}$ of the solid phases considered in the modeling.

\begin{tabular}{lll}
\hline Mineral & Reaction of formation & $\operatorname{LogK}\left(25^{\circ} \mathrm{C}\right)$ \\
\hline Pu-doped $\mathrm{UO}_{2}$ & $0.997 \mathrm{U}^{4+}+0.003 \mathrm{Pu}^{4+}+2 \mathrm{H}_{2} \mathrm{O} \Leftrightarrow\left(\mathrm{U}_{0,997} \mathrm{Pu}_{0,003}\right) \mathrm{O}_{2}$ & $-500^{*}$ \\
& $+4 \mathrm{H}^{+}$ & \\
$\mathrm{UO}_{2} \cdot 2 \mathrm{H}_{2} \mathrm{O}(\mathrm{am})$ & $\mathrm{U}^{4+}+4 \mathrm{H}_{2} \mathrm{O} \Leftrightarrow \mathrm{UO}_{2} \cdot 2 \mathrm{H}_{2} \mathrm{O}(\mathrm{am})+4 \mathrm{H}^{+}$ & $-1.500,-0.600^{* *}$ \\
Schoepite & $\mathrm{UO}_{2}{ }^{2+}+3 \mathrm{H}_{2} \mathrm{O} \Leftrightarrow \mathrm{UO}_{3} \cdot 2 \mathrm{H}_{2} \mathrm{O}+2 \mathrm{H}^{+}$ & -5.960 \\
\hline $\begin{array}{l}\text { Fe_metal (anoxic } \\
\text { corrosion) }\end{array}$ & $\mathrm{Fe}^{2+}+\mathrm{H}_{2} \Leftrightarrow \mathrm{Fe}+2 \mathrm{H}^{+}$ & $-500^{*}$ \\
Goethite & $\mathrm{Fe}^{3+}+2 \mathrm{H}_{2} \mathrm{O} \Leftrightarrow \mathrm{FeO}(\mathrm{OH})+3 \mathrm{H}^{+}$ & -0.390 \\
Siderite & $\mathrm{Fe}^{2+}+\mathrm{CO}_{3}{ }^{2-} \Leftrightarrow \mathrm{FeCO}_{3}$ & 10.800 \\
\hline Calcite & $\mathrm{Ca}^{2+}+\mathrm{CO}_{3}{ }^{2-} \Leftrightarrow \mathrm{CaCO}_{3}$ & 8.480 \\
Strontianite & $\mathrm{Sr}^{2+}+\mathrm{CO}_{3}{ }^{2-} \Leftrightarrow \mathrm{SrCO}_{3}$ & 9.270
\end{tabular}

$\left({ }^{*}\right)$ Arbitrary logK to impose a kinetic control only. $(* *)$ Our experimental results were close to the solubility limit of $\mathrm{UO}_{2} \bullet \mathrm{XH}_{2} \mathrm{O}(\mathrm{am})$ but in the lower uncertainty range (Neck \& Kim, 2001); i.e. $3 \times 10^{-10}$ mol. $L^{-1}$. A sensitivity analysis on the LogK (between -1.5 and -0.6 ) was performed (see Fig. 1).

\section{Table 5.}

Comparison between experiment and modeling mass balances for uranium released after 450 days.

\begin{tabular}{lll}
\hline & In solution $[\mu \mathrm{g}]$ & Total $[\mu \mathrm{g}]$ \\
\hline Experiment & 0.01 & 10 \\
Modeling & & \\
Hypothesis $1-\mathrm{Fe}(\mathrm{II}) / \mathrm{U}(\mathrm{VI})$ reaction & 0.02 & 1200 \\
Hypothesis 2 $-\mathrm{Fe}(\mathrm{II}) / \mathrm{H}_{2} \mathrm{O}_{2}$ reaction & 0.02 & 6 \\
\hline
\end{tabular}

